\title{
Contemporary Drug Treatment of Advanced Heart Failure with Reduced Ejection Fraction
}

\author{
Julie K. K. Vishram-Nielsen ${ }^{1}$ - Daniela Tomasoni ${ }^{2} \cdot$ Finn Gustafsson ${ }^{1,3} \cdot$ Marco Metra $^{2}$
}

Accepted: 16 December 2021 / Published online: 3 February 2022

(c) The Author(s) 2022

\begin{abstract}
The introduction of multiple new pharmacological agents over the past three decades in the field of heart failure with reduced ejection fraction (HFrEF) has led to reduced rates of mortality and hospitalizations, and consequently the prevalence of HFrEF has increased, and up to $10 \%$ of patients progress to more advanced stages, characterized by high rates of mortality, hospitalizations, and poor quality of life. Advanced HFrEF patients often show persistent or progressive signs of severe HF symptoms corresponding to New York Heart Association class III or IV despite being on optimal medical, surgical, and device therapies. However, a subpopulation of patients with advanced HF, those with the most advanced stages of disease, were often insufficiently represented in the major trials demonstrating efficacy and tolerability of the drugs used in HFrEF due to exclusion criteria such as low BP and kidney dysfunction. Consequently, the results of many landmark trials cannot necessarily be transferred to patients with the most advanced stages of HFrEF. Thus, the efficacy and tolerability of guidelinedirected medical therapies in patients with the most advanced stages of HFrEF often remain unsettled, and this knowledge is of crucial importance in the planning and timing of consideration for referral for advanced therapies. This review discusses the evidence regarding the use of contemporary drugs in the advanced HFrEF population, covering components such as guideline HFrEF drugs, diuretics, inotropes, and the use of HFrEF drugs in LVAD recipients, and provides suggestions on how to manage guideline-directed therapy in this patient group.
\end{abstract}

\section{Introduction}

Pharmacological advancements have revolutionized the field of heart failure (HF) with the introduction of angiotensin-converting enzyme inhibitors (ACEI) [1, 2], angiotensin receptor blockers (ARBs) [3], beta-blockers (BB) [4], mineralocorticoid receptor antagonists (MRA) [5], the newer angiotensin receptor neprilysin inhibitors (ARNI) [6] and sodium-glucose cotransporter 2 (SGLT-2) inhibitors $[7,8]$, all of which have reduced the rates of mortality

Marco Metra

metramarco@libero.it

1 Department of Cardiology, Rigshospitalet, University of Copenhagen, Copenhagen, Denmark

2 Cardiology, ASST Spedali Civili, Department of Medical and Surgical Specialties, Radiological Sciences and Public Health, University of Brescia, Brescia, Italy

3 Department of Clinical Medicine, University of Copenhagen, Copenhagen, Denmark and hospitalization in patients with HF with reduced ejection fraction (HFrEF). As a consequence, the prevalence of HF has risen and now constitutes an estimated 64.3 million people worldwide [9]. Up to $10 \%$ of patients with HF gradually progress to more advanced stages [10], characterized by high mortality, frequent hospitalizations, marked limitation of exercise capacity, poor quality of life (QoL), and hemodynamic impairment [11]. Although advanced HF is recognized as a distinct entity by professional societies [11-16], to date no consensus definition of advanced HF exists. However, the most updated Heart Failure Association-ESC criteria for defining advanced HF (Table 1) provides substantial consensus [13], and, in fact, this definition has been adopted by recent work [17, 18]. In addition, in the recent universal definition of HF, endorsed by the HF Society of America, HF Association of the European Society of Cardiology (ESC) and Japanese HF Society, there is a general consensus that advanced HF is identified with the stage $\mathrm{D}$ of the American College of Cardiology/American Heart Association (ACC/AHA) classification [19]. 


\section{Key Points}

Heart-failure (HF)-related pharmacotherapy has evolved significantly, and currently advanced heart failure with reduced ejection fraction (HFrEF) patients may benefit from both traditional HF drugs (angiotensin-converting enzyme inhibitor, angiotensin receptor blocker, betablocker, mineralocorticoid receptor antagonist) and diuretics, as well as from the more recent SGLT-2 inhibitors, intravenous ferric caboxymaltose, and omecamtiv mecarbil, and the data for these newer drug treatments are accumulating.

Inotropes are only indicated in advanced HFrEF patients who show persistent clinical signs of low cardiac output or high filling pressures despite the use of conventional therapy and can be used as a bridge to mechanical circulatory support, heart transplantation, or palliation.

HFrEF drugs also play an important role in LVAD recipients in relation to lowering risk of complications as well as for improving myocardial recovery.

It is universally accepted that these patients show persistent or progressive signs of severe HF symptoms corresponding to New York Heart Association (NYHA) class III or IV, despite being on optimal medical, surgical, and device therapies. Consistent with this general acceptance, a recent review of the enrollment criteria used to define advanced HF in 134 clinical trials found that the most commonly used criterion was in fact NYHA class with a range from II to IV, followed by left-ventricular ejection fraction (LVEF) with a cutoff range between 20 and $45 \%$. Beyond these two parameters, a wide array of criteria have been used, with inconsistencies in both criteria selection and quantitative cut-off points [20].

While recognizing that definitions of advanced HF vary in the landmark trials, it is clear that a subpopulation of patients with the most advanced stages of disease were often excluded from the major trials demonstrating efficacy of the drugs used in HFrEF due to exclusion criteria such as low blood pressure (BP) and kidney dysfunction. Consequently, the results of the landmark trials cannot necessarily be transferred to patients with the most advanced stages of HFrEF. This is important for several reasons. First, clinicians should be aware of the degree of efficacy that can be expected from guideline-directed medical therapy in patients with advanced $\mathrm{HF}$ in the planning and timing of consideration for referral for advanced therapies like left-ventricular assist device (LVAD) or heart transplantation (HTx) [21]. Further, tolerability of guideline-directed therapy in patients with advanced HF is often not comparable to that in non-advanced patients, and advanced HF patients may require closer follow-up during initiation and up-titration of medications.

The aim of this review is to discuss the evidence regarding the use of contemporary drugs in patients with advanced HFrEF and to provide suggestions on how to manage gudieline-directed therapy in this patient group (Fig. 1).

Table 1 Updated HFA-ESC criteria for defining advanced HF

All the following criteria must be present despite optimal guideline-directed treatment:

1. Severe and persistent symptoms of HF (NYHA class III or IV)

2. Severe cardiac dysfunction defined by a reduced LVEF $\leq 30 \%$, isolated RV failure (i.e., ARVC) or non-operable severe valve abnormalities or congenital abnormalities or persistently high (or increasing) BNP or NT-proBNP values and data of severe diastolic dysfunction or LV structural abnormalities according to the ESC definition of HFpEF and HFmrEF

3. Episodes of pulmonary or systemic congestion requiring high-dose intravenous diuretics (or diuretic combinations) or episodes of low output requiring inotropes or vasoactive drugs or malignant arrhythmias causing $>1$ unplanned visit or hospitalization in the last 12 months

4. Severe impairment of exercise capacity with inability to exercise or low 6MWTD $(<300 \mathrm{~m})$ or pVO2 $(<12-14 \mathrm{~mL} / \mathrm{kg} / \mathrm{min})$, estimated to be of cardiac origin

In addition to the above, extra-cardiac organ dysfunction due to heart failure (i.e., cardiac cachexia, liver, or kidney dysfunction) or type 2 pulmonary hypertension may be present but are not required

Criteria 1 and 4 can be met in patients who have cardiac dysfunction (as described in criterion \#2), but who also have substantial limitation due to other conditions (i.e., severe pulmonary disease, non-cardiac cirrhosis, or most commonly by renal disease with mixed etiology). These patients still have limited quality of life and survival due to advanced disease and warrant the same intensity of evaluation as someone in whom the only disease is cardiac, but the therapeutic options for these patients are usually more limited

6MWTD 6-minute walk test distance, $A R V C$ arrhythmogenic right ventricular cardiomyopathy, BNP B-type natriuretic peptide, ESC European Society of Cardiology, $H F A$ Heart Failure Association, $H F m r E F$ heart failure with mid-range ejection fraction, $H F p E F$ heart failure with preserved ejection fraction, $L V$ left ventricular, $L V E F$ left ventricular ejection fraction, NT-proBNP N-terminal pro-B-type natriuretic peptide, NYHA New York Heart Association, $p V O 2$ peak exercise oxygen consumption, $R V$ right ventricular

Crespo-Leiro MG, et al. EHJ.2018,20:1505-1535 


\section{Available Drugs with Effects on Outcome}

The front-line treatment recommended by current HF clinical practice guidelines in symptomatic HFrEF patients includes a triple neurohormonal blockage with an ACEI or ARNI (or ARB in those who are intolerant to both), a $\mathrm{BB}$, and an MRA, unless contraindicated or not tolerated, plus SGLT-2 inhibitors [22, 23]. However, a major challenge in patients with advanced HFrEF is that they often do not tolerate neurohormonal modulators or that, if administered, they cannot be titrated to their target doses because of side effects, mostly hypotension and/or kidney failure $[24,25]$. Evidence indicates that these agents are in fact administered at lower rates and doses in this patient population [22-26]. Plausible explanations of the intolerability of neurohormonal modulators in advanced HFrEF patients could be related to the progression of the HF disease itself leading to a low cardiac output state with hypotension and renal dysfunction to follow, or it could be related to the direct effect of the neurohormonal modulators, or a combination of both [11, 24, 25]. Regardless of the underlying cause of the intolerability of neurohormonal modulators, the use of suboptimal doses of these agents in advanced HF patients is related to a very poor prognosis [27-29]. Other disease-modifying drugs that have shown benefit in
HFrEF patients include digoxin, I $f$-channel blockers, the combination of hydralazine and isosorbide dinitrate, and, to a larger extent, as shown by the favorable results of the recent trials, SGLT-2 inhibitors. All of these drugs can be add-on therapies $[16,23,30]$. In the following, we will review the evidence from clinical trials for each guidelinerecommended HFrEF drug group, with particular emphasis on the impact of the results on patients with advanced HFrEF (Table 2).

\subsection{Neurohormonal Modulators}

The renin-angiotensin aldosterone system (RAAS) maintains the regulation of BP, and fluid and electrolyte homeostasis. In chronic HF, the RAAS is activated early due to reduced urinary sodium excretion, decreased afferent glomerular arteriolar pressure, as well as the sympathetic activation that is particularly prominent in the kidney. These processes are fundamental to the left ventricle (LV) remodelling process that follows myocardial injury or inflammation, and hence, they play a crucial part in the progression of HF. Thus, drugs that block the RAAS at key steps in its pathway or block the activity of the sympathetic nervous system are desirable, and indeed this is the main role of the neurohormonal modulators [31-33].

\section{Management of advanced HFrEF patients}

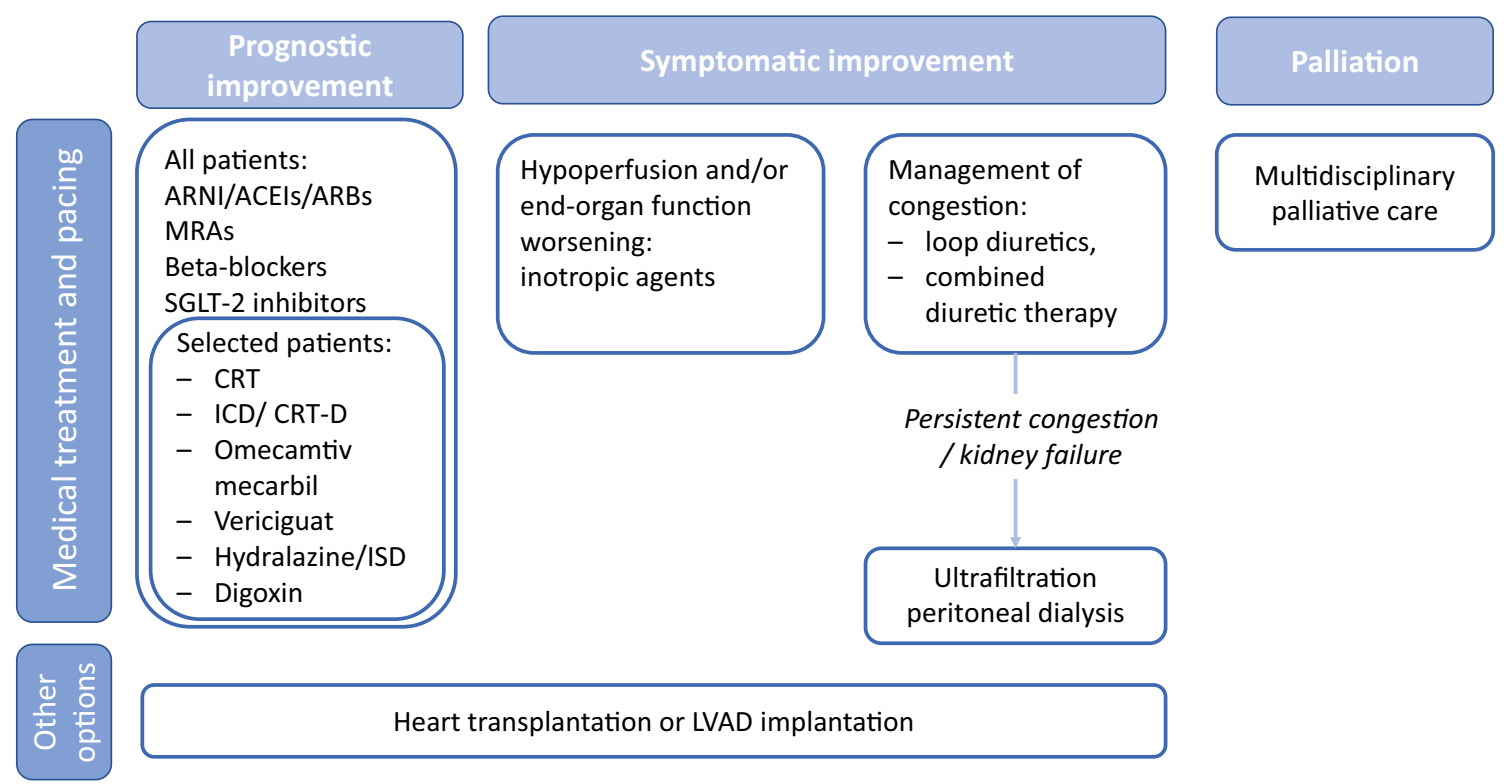

Fig. 1 Management of advanced HFrEF patients. HFrEF, heart failure with reduced ejection fraction; ARNI, angiotensin-receptorneprilysin inhibitor; ACEIs, angiotensin-converting enzyme inhibitors; ARBs, angiotensin receptor blockers; MRAs, mineralocorticoid receptor antagonists; SGLT-2 inhibitors, sodium-glucose co-transporter-2.; CRT, cardiac resynchronization therapy; ICD, implantable cardioverter defibrillator; ISD, isosorbide dinitrate; LVAD, left ventricular assist device. 


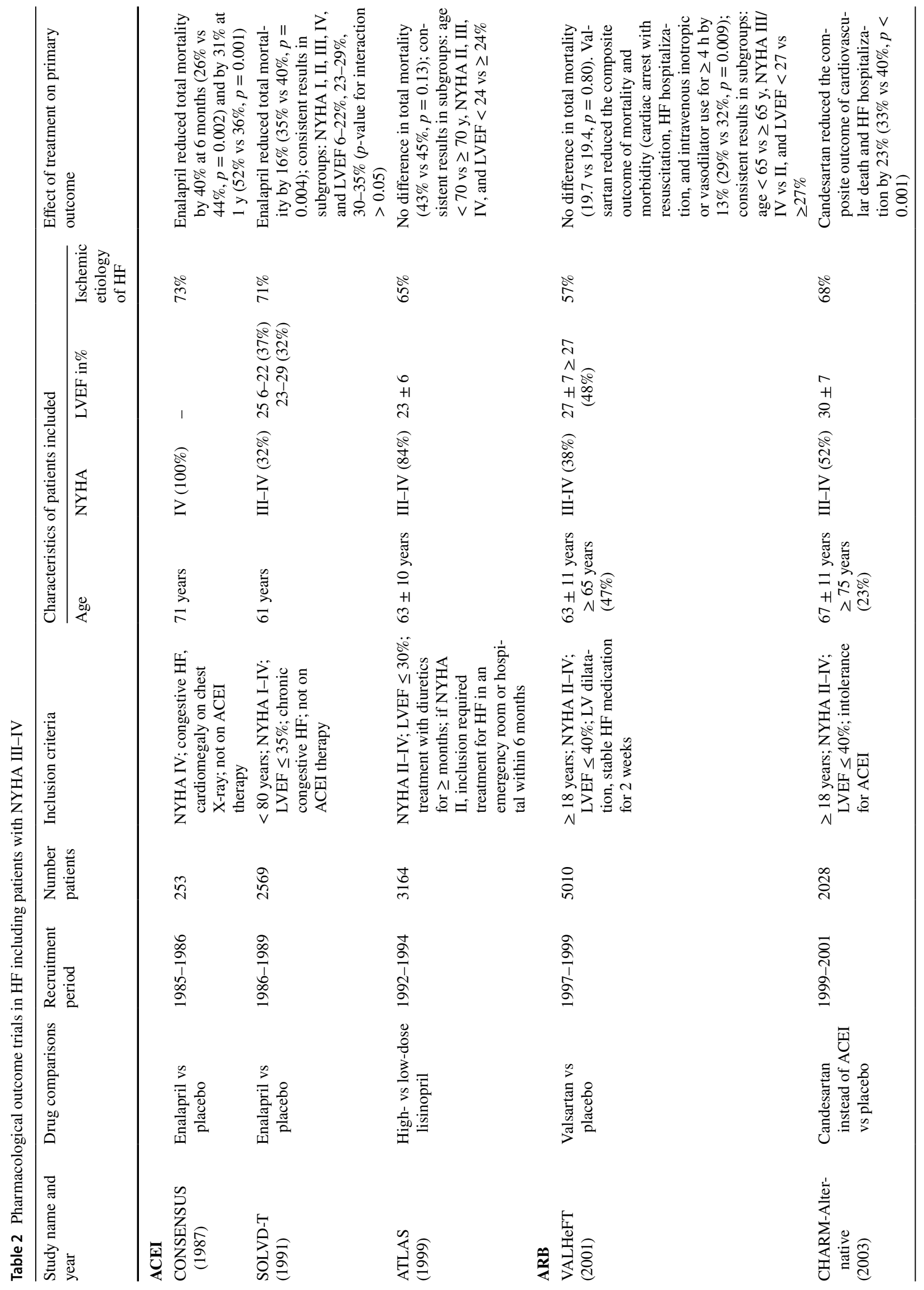




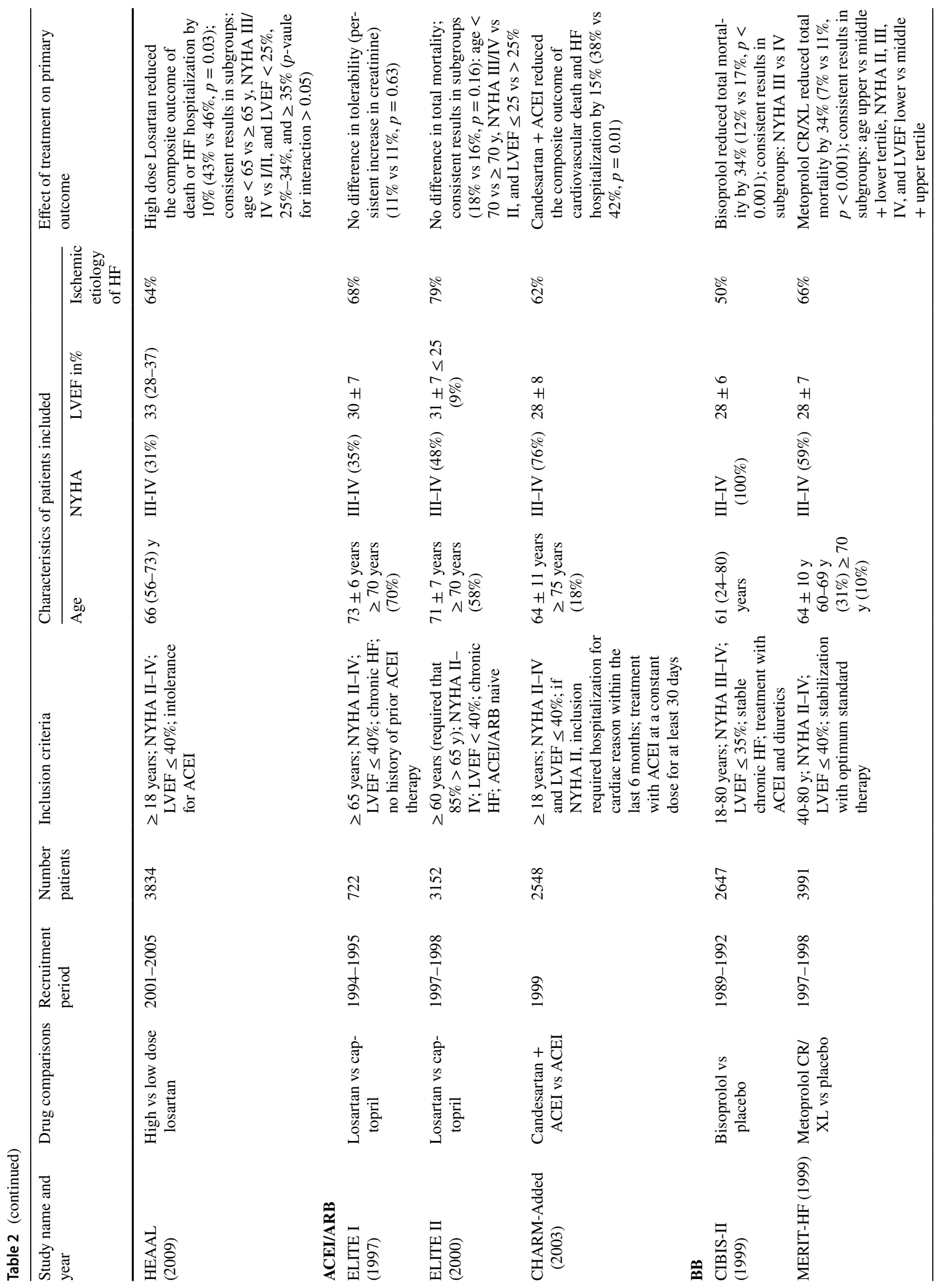




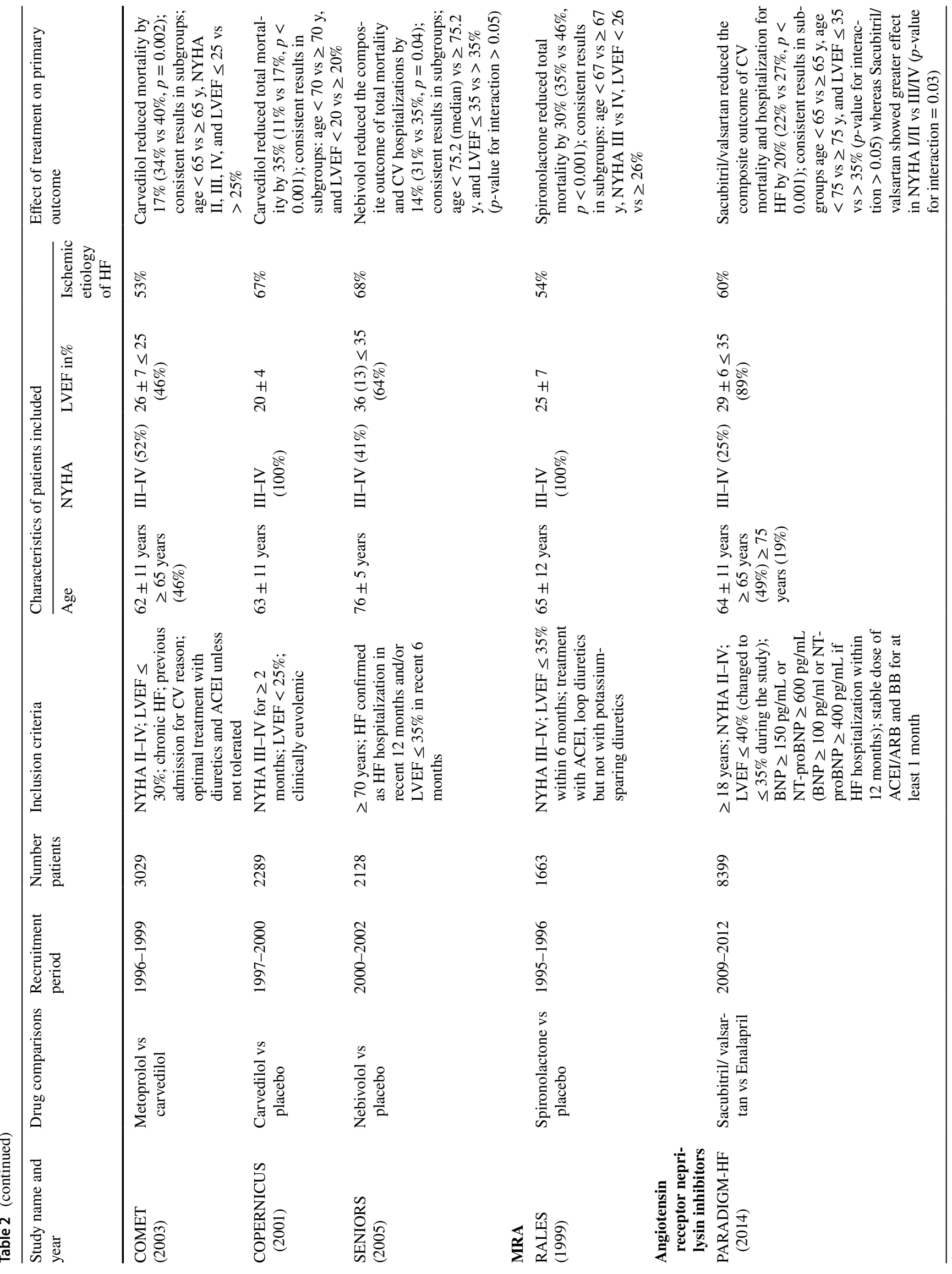




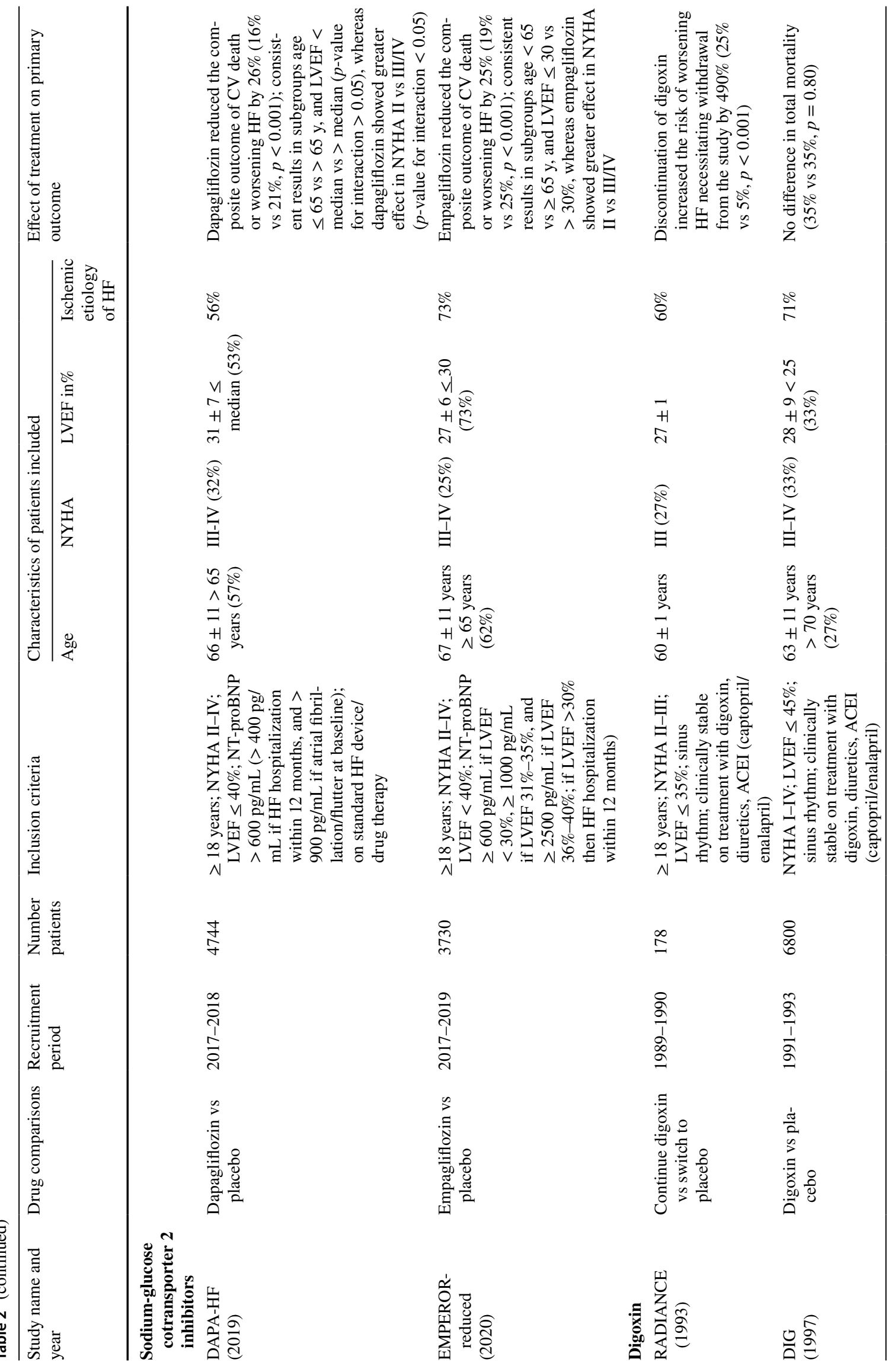




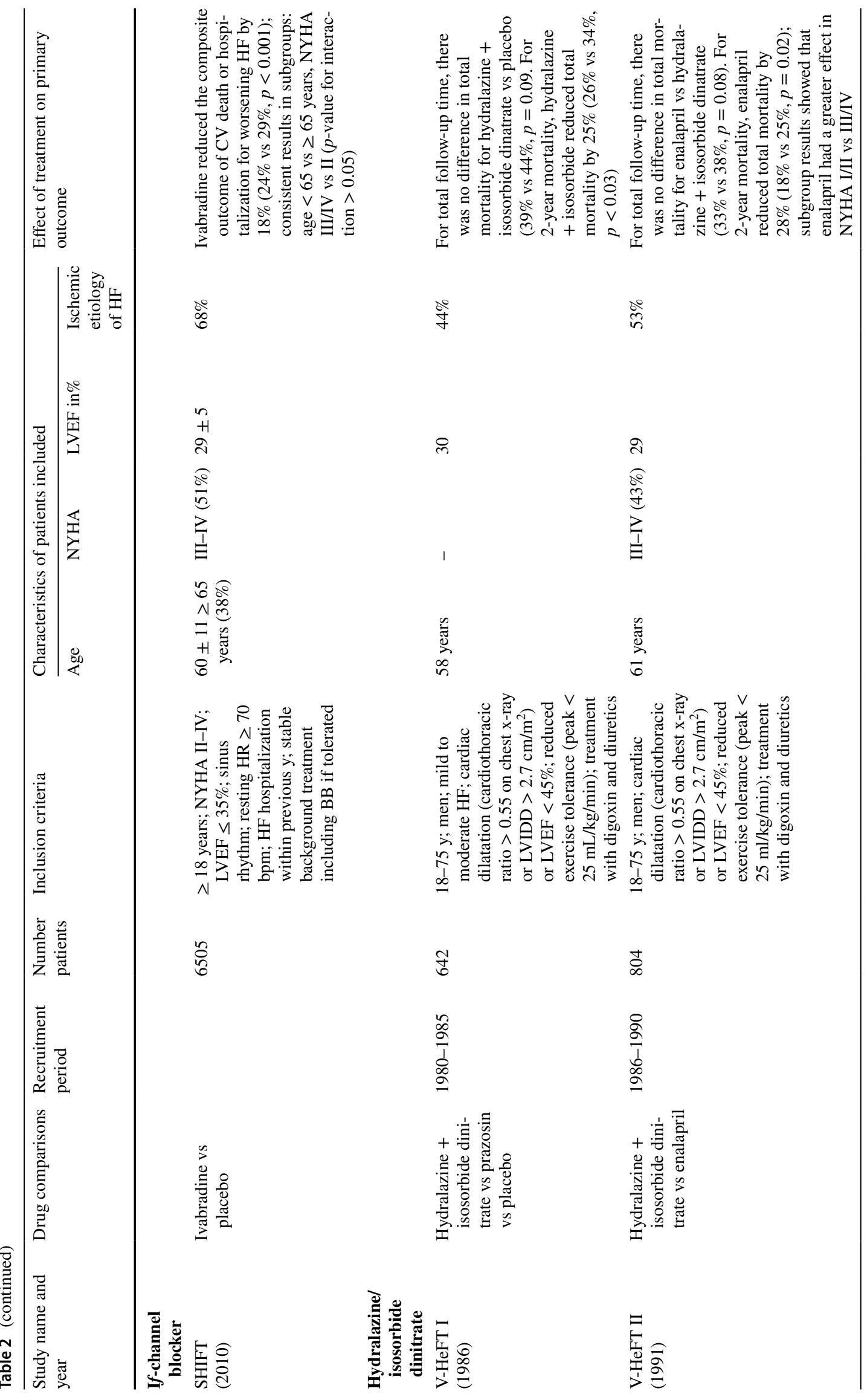




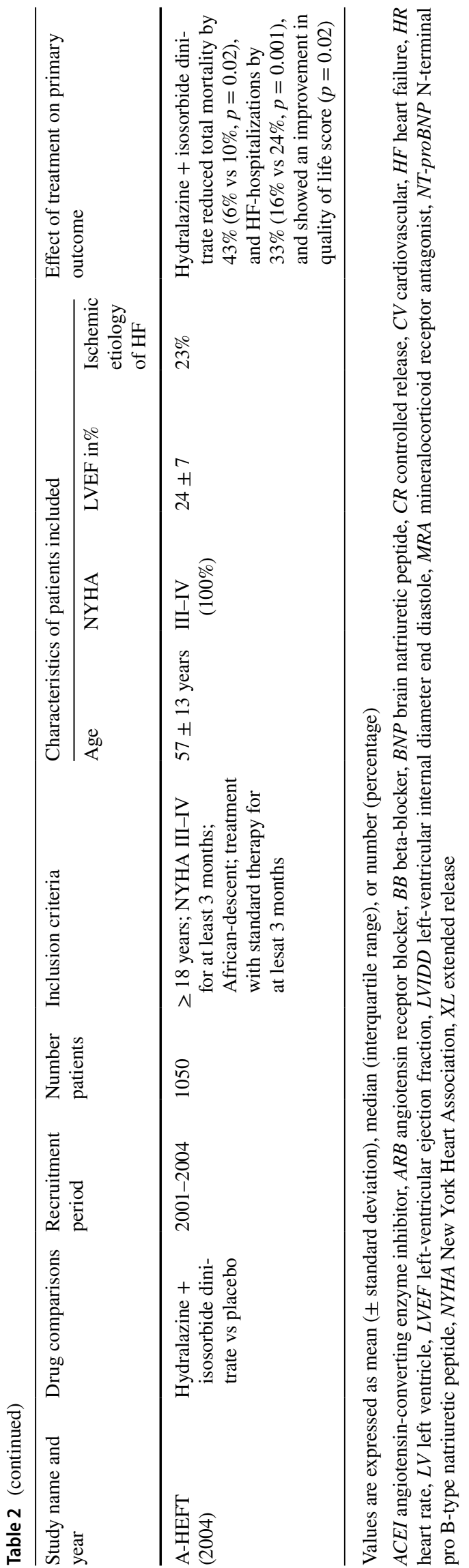

\subsubsection{Angiotensin-Converting Enzyme Inhibitors and Angiotensin Receptor Blockers}

Whereas ACEIs block the angiotensin-converting enzyme, ARBs block the angiotensin II type I receptor, and both of these RAAS inhibitors have indeed shown their beneficial impact on mortality and morbidity in HFrEF patients, albeit the evidence remains most solid for ACEIs [1-3, 34-39]. The Cooperative North Scandinavian Enalapril Survival Study (CONSENSUS) [1] was the first randomized clinical trial to show that enalapril compared to placebo reduced total mortality by $40 \%$ at 6 months $(p=0.002)$ and by $31 \%$ at 1 year $(p=0.001)$ in $253 \mathrm{HFrEF}$ patients with mean age 71 years and symptoms corresponding to NYHA class IV. These results were confirmed in a larger study consisting of 2569 HFrEF patients with mean age 61 years, mean LVEF $25 \%$, and symptoms corresponding to NYHA class III-IV in $32 \%$ of patients [2]. In the latter study, the results were stratified by age, NYHA class, and LVEF, and showed consistent findings in patients with more severe signs and symptoms of HF.

For ARBs, studies have shown a reduction in the combined outcome of mortality and morbidity but not mortality alone in HFrEF patients who were either switched to candesartan due to ACEI intolerance [35] or who received an ARB on top of background therapy with ACEI $[3,39]$. In these studies, patients were on average in their 60s with a LVEF range between 27 and 30\%, and 38-76\% experienced NYHA class III-IV symptoms. Only two studies directly compared ACEIs with ARBs in $3874 \mathrm{HFrEF}$ patients aged $>60$ years with a mean LVEF around $30 \% \pm 7 \%$, and $35-48 \%$ with NYHA class III-IV symptoms [37, 38]. These studies showed no difference in tolerability defined as persistent increase in creatinine as well as in total mortality between these two drugs. Last, it is worth noting that evidence indicates that the beneficial effects of ACEIs and ARBs are dose-dependent and therefore it is crucial that target doses of these drugs, as used in the clinical trials, are reached, otherwise they might not be effective in clinical practice $[34,36]$. The findings of these studies were consistent in sub-group analyses in patients with more severe signs and symptoms of HF.

\subsubsection{Beta-Blockers}

Beta-blockers exude their effect by inhibiting the chronotropic and inotropic effects of the beta- 1 receptors, which in turn decreases the excessive activity of the sympathetic nervous system [33]. Studies have consistently shown that compared to placebo, beta-blockers reduce both mortality and morbidity in symptomatic but stable HFrEF patients who are on optimum medical therapies [4, 40-43]. The HFrEF patients in these previous studies were, on average, in 
their 60s with a LVEF range between 20 and 28\%, and symptoms corresponding to NYHA class III-IV in 52-100\%. The Cardiac Insufficiency Bisoprolol Study II (CIBIS-II) [4] and the Carvedilol Prospective Randomized Cumulative Survival (COPERNICUS) [42] trial included a total of 4936 HFrEF patients who only had severe symptoms corresponding to NYHA III-IV, and in the latter study the mean LVEF was $20 \% \pm 4 \%$, indicating that the beneficial effects of BBs are also seen in patients with severe symptoms and signs of HF. This beneficial effect of BBs in more severe HFrEF patients was further confirmed by the fact that all of the previously mentioned studies had carried out sub-group analyses in patients with severe signs and symptoms and replicated the beneficial findings of BBs. Lastly, it is important to note that previous work did not include HFrEF patients who were congested or decompensated, and hence BBs are not recommended in this patient population [23].

\subsubsection{Mineralocorticoid Receptor Antagonists}

Mineralocorticoid Receptor Antagonists inhibit the RAAS by blocking the receptors that bind aldosterone and other corticosteroids [32], and these agents have indeed shown beneficial effects on the reduction of mortality and morbidity in HFrEF patients with severe symptoms [5]. The landmark study, Randomized Aldactone Evaluation Study (RALES) [5] included 1663 HFrEF patients on standard therapies with an ACEI and non-potassium-sparing loop diuretics, with mean age of $65 \pm 12$ years, LVEF $25 \% \pm 7 \%$, and symptoms corresponding to NYHA class III-IV in $100 \%$. Compared to placebo, spironolactone reduced total mortality by $30 \%$ and hospitalization for worsening HF by 35\% (both $p<0.001$ ), and these results were consistent in sub-group analyses in patients with more severe signs and symptoms of HFrEF. However, despite the beneficial effects of the MRAs, caution should be exercised, especially in patients with severe HFrEF and renal impairment, as MRA treatment may be associated with worsening renal function (WRF) and hyperkalemia [44, 45]. Finerenone is a third-generation MRA with higher selectivity toward the mineralocorticoid receptor compared to spironolactone, and therefore, may reduce the risk of hyperkalemia and WRF [46]. In two recent large double-blind trials [47, 48], finerenone, compared to placebo, reduced the risk of chronic kidney disease (CKD) progression and cardiovascular (CV) events in patients with CKD and diabetes type 2 .

\subsubsection{Angiotensin Receptor Neprilysin Inhibitor}

ARNIs consist of an ARB (valsartan), which acts on the RAAS by inhibiting the angiotensin II type I receptor, and a neprilysin inhibitor (sacubitril), which slows the degradation of bradykinin and peptides including natriuretic peptides and hence plays an important role in myocardial relaxation and anti-remodeling. The Prospective Comparison of ARNI with ACEI to Determine Impact on Global Mortality and Morbidity in HF (PARADIGM-HF) [6] was the landmark trial which compared ARNI with Enalapril in 8399 HFrEF patients on optimal medical therapy, with mean age $64 \pm 11$ years, LVEF $29 \% \pm 6 \%$, and $25 \%$ with NYHA class III-IV symptoms. The trial showed that ARNI reduced the composite outcome of $\mathrm{CV}$ mortality and HFrelated hospitalization by $20 \%$ compared to enalapril $(p<$ 0.001 ). However, sub-group analyses indicated an interaction $(p=0.03)$ for NYHA class suggesting less efficacy of ARNI in HFrEF patients with severe symptoms. In addition, main safety issue when initiating therapy with ARNI in clinical practice, as reported in the study, was symptomatic hypotension. Declining renal function was less frequently seen in the ARNI group compared to enalapril [6]. A recent smaller trial (NCT02816736), the Entresto In Advanced HF (LIFE) trial, compared ARNI to valsartan in an advanced HF population defined as reporting NYHA class IV symptoms within the last 3 months, LVEF $<35 \%$, and elevated $\mathrm{N}$-terminal pro B-type natriuretic peptide (NT-proBNP) $>$ $800 \mathrm{pg} / \mathrm{mL}$ or brain natriuretic peptide (BNP) $>250 \mathrm{pg} / \mathrm{mL}$, as well as one other defined marker of advanced disease. The primary endpoint was change in NT-proBNP after 24 weeks. The trial stopped inclusion prematurely because of COVID19 , but 335 of 400 patients completed the study. ARNI was not associated with a greater decrease in NT-proBNP compared with valsartan nor were there any signals of improved clinical outcomes (late breaking clinical trials, ACC 2021). Given the size of the study, no firm conclusions regarding the use of ARNI in advanced HF can be made, but it seems reasonable to conclude that clinicians should not expect that ARNI can be better tolerated than ACEIs and that the dismal prognosis in advanced HF will be modified significantly by exchanging an ACEI or an ARB with an ARNI [21].

Taken together, although patients with the most advanced stages of HFrEF tend to be underrepresented in the landmark trials with neurohormonal modulators, it appears that their beneficial effects may be maintained also in these patients. Even though patients with advanced HF are more likely to develop symptomatic hypotension and/or renal insufficiency, treatment with these agents must also be considered in patients with advanced HF.

\subsection{Sodium-Glucose Cotransporter $\mathbf{2}$ Inhibitors}

The SGLT-2 inhibitors have shown beneficial effects on mortality and morbidity in HFrEF patients in two recent trials [7, 8], and are consequently recommended as an add-on therapy in symptomatic HFrEF patients on optimum standard therapy [23, 30, 49-51]. In the Dapagliflozin and Prevention of Adverse-Outcomes in Heart Failure (DAPA-HF) 
[7] trial, dapagliflozin was compared with placebo in 4744 HFrEF patients with mean age $66 \pm 11$ years, LVEF $31 \% \pm$ $7 \%$, and $32 \%$ in NYHA class III-IV. Compared to placebo, dapagliflozin reduced the composite outcome of CV death or worsening $\mathrm{HF}$ by $26 \%$. Similar results using an almost identical patient population were seen for empagliflozin in the Empagliflozin Outcome Trial in Patients With Chronic Heart Failure With Reduced Ejection Fraction (EMPERORHF) [8] trial. However, in both studies sub-group analyses indicated that the beneficial effects of the SGLT-2 inhibitors were numerically greater in HFrEF patients in NYHA class II compared to III-IV and as such it is less clear whether an improvement in outcome can be expected when patients with advanced HF are treated. However, the non-selective SGLT inhibitor sotaglifozin reduced cardiovascular deaths and HF hospitalizations or urgent visits, compared with placebo in patients with diabetes and a recent hospitalization for $\mathrm{HF}$ [52]. Second, a recent placebo-controlled study examined empagliflozin in patients with acute decompensated HF and found that treatment with an SGLT-2 inhibitor increased diuresis significantly [53], and the EMPULSE trial, a randomized placebo-controlled trial showing the efficacy and safety of the in-hospital initiation of empaglifozin versus placebo in patients hospitalized for HF, will be published shortly [54]. Moreover, studies in patients with chronic HFrEF with and without diabetes have clearly shown that SGLT-2 inhibitors significantly reduce plasma- and extracellular volume [55, 56], and as such SGLT-2 inhibitors could have an important place in the management of advanced HF patients, who frequently present with fluid overload. However, more studies are required to document this. Currently, we believe that every effort should be made to add SGLT-2 inhibitors to the therapeutic regimen of patients with advanced $\mathrm{HF}$, similarly to $\mathrm{HFrEF}$ patients without advanced symptoms, as tolerability is exceptional, and the current evidence suggests a "blanket effect" across the spectrum of HF. However, in order not to delay assessment of patients with advanced HF for LVAD implantation or HTx if indicated, the add-on of SGLT-2 inhibitors to the therapeutic regimen could occur simultaneously as the referral for advanced HF therapies.

\subsection{Iron}

Iron deficiency is common in the HFrEF population and is associated with a worse prognosis $[57,58]$. Current guidelines recommend that intravenous ferric carboxymaltose should be considered in symptomatic patients with low iron status in order to alleviate HF symptoms and improve exercise capacity and QoL as well as reduce risk of HF hospitalization [23]. This recommendation is based on three randomized controlled trials in iron-deficient $\mathrm{HF}$ patients [59-61]. The first two studies only included HFrEF patients with symptoms corresponding to NYHA class II and III, and for the latter, a LVEF $\leq 45 \%$ was required. Whereas in the Ferinject Assessment in Patients with Iron Deficiency and Chronic Heart Failure (FAIR-HF) [59] trial 83\% of patients were in NYHA class III, this was only the case in $43 \%$ of patients in the Ferric Carboxymaltose Evaluation on Performance in Patients with Iron Deficiency in Combination with Chronic HF (CONFIRM-HF) [60] trial. The mean LVEF in these two trials was $32 \% \pm 6 \%$ and $37 \% \pm 7 \%$, respectively. Although subgroup analyses showed similar benefits of intravenous ferric carboxymaltose in NYHA class II versus III, the majority of patients included in these two trials did not have advanced HF and thus data with intravenous ferric carboxymaltose in advaned HF patients are not yet clear. The results of the more recent Randomized Double-blind Placebo Controlled Trial Comparing the Effect of Intravenous Ferric Carboxymaltose on Hospitalizations and Mortality in Iron Deficient Subjects Admitted for Acute Heart Failure (AFFIRM-AHF) show that intravenous ferric carboxymaltose is beneficial also in patients hospitalized for HF [61]. AFFIRM-AHF showed that treatment with intravenous ferric caboxymaltose in the stabilized phase of patients with a $\mathrm{HF}$ hospitaliation was safe and reduced the risk of HF rehospitalizations. In this trial, the HF patients included had a mean age of $71 \pm 11$ years, $\mathrm{LVEF} 33 \% \pm 10 \%(\mathrm{LVEF}<$ $25 \%$ in $20 \%$ of patients), and $53 \%$ in NYHA class III or IV, and sub-group analyses indicated that the beneficial effect of intravenous ferric caboxymaltose was also seen in patients with more severe signs and symptoms of HF.

\subsection{Digoxin}

Digoxin is known to modulate vagal tone, and in HFrEF patients it has an inhibitory effect on the sympathetic nerve activity [62]. However, the prognostic benefits of using cardiac glycosides in HFrEF patients who are in sinus rhythm is questionable $[63,64]$. In the Randomized Assessment of Digoxin on Inhibitors of the Angiotensin Converting Enzyme (RADIANCE) [63] trial, which compared the continuation versus discontinuation of digoxin in $178 \mathrm{HFrEF}$ patients in sinus rhythm with mean age $60 \pm 1$ years, LVEF $27 \% \pm 1 \%$, and where $73 \%$ were in NYHA class II and $23 \%$ in NYHA class III, the continuation of digoxin had a favorable effect on worsening HF. This study was conducted in the pre-BB era and as such the results cannot be extrapolated to current HF populations. However, in patients with more advanced $\mathrm{HF}$ who are intolerant of BBs, the results may very well still be relevant. In the larger Digitalis Investigation Group (DIG) [64] trial of $6800 \mathrm{HF}$ patients in sinus rhythm with mean age $63 \pm 11$ years, $\mathrm{LVEF} 28 \% \pm 9 \%$, and $33 \%$ in NYHA class III-IV did not find a beneficial effect of digoxin on mortality compared to placebo. Consequently, current guidelines recommend that in symptomatic HFrEF 
patients, digoxin may be considered especially in those with atrial fibrillation and rapid ventricular rate, and when other therapeutic options cannot be pursued [23]. A current ongoing trial, the Digitoxin to Improve outcomes in patients with advanced chronic HF (DIGIT-HF) [65], which compares digoxin with placebo in HFrEF patients with and without atrial fibrillation in NYHA class III-IV and LVEF $\leq 40 \%$ (or NYHA class II and LVEF $\leq 30 \%$ ) will hopefully provide more clarification on the use of digoxin in advanced HF.

\subsection{If-channel Blocker}

Ivabradine slows the elevated heart rate that is often seen in HFrEF patients, through inhibition of the If channel in the sinus node [23]. Ivabradine has been shown to exert a modest beneficial effect on prognosis in HFrEF. For instance, in the Systolic Heart Failure Treatment with the I $f$ Inhibitor Ivabradine Trial (SHIFT) [66], ivabradine was compared to placebo in $6505 \mathrm{HFrEF}$ patients on optimum medical therapy with a heart rate $\geq 70$ beats per minute, and with mean age $60 \pm 11$ years, LVEF $29 \% \pm 5 \%$, and $51 \%$ in NYHA class III-IV, and the results showed that ivabradine reduced the composite outcome of CV death or hospitalization for worsening HF by $18 \%$. Sub-group analyses indicated that the results were consistent in patients with severe signs and symptoms of HFrEF. However, as very few studies have been carried out, and with only a relatively small population of advanced HF patients, the information on the effects of ivabradine in advanced HF is limited. Nevertheless, current guidelines recommend that ivabradine be used in symptomatic HFrEF patients who are in sinus rhythm and with a heart rate of $\geq 75$ beats per minutes [23]. Of note, ivabradine has a minor effect on BP, and consequently this agent could have a potential in those advanced HF patients in whom tachycardia persists and where the use of BBs is limited due to hypotension [67].

\subsection{Hydralazine and Isosorbide Dinitrate}

Whereas hydralazine has an arterial dilatory effect, isosorbide dinitrate primarily has a venodilatory effect, and the reason for using these two vasodilatory drugs in combination was to achieve a balanced decrease in LV afterload and preload [67]. Previous work has shown beneficial effects of hydralazine and isosorbide dinitrate in reducing mortality and morbidity in HFrEF patients. However, these drug agents were phased out as first-line treatment when the ACEI trials started to show significant beneficial effects of ACEI in the whole spectrum of HFrEF patients [68-70]. In the Veterans Administration Heart Failure Trial (V-HEFT-I) [68], hydralazine and isosorbide dinitrate compared to placebo reduced mortality at 2 years but not at total follow-up time, and in V-HEFT-II [69], these agents were not superior to enalapril at 2 years, whereas there were no differences between hydralazine and isosorbide dinitrate and enalapril at total follow-up time. Both studies included men who were treated with digoxin and diuretics, with mean age 58-61 years and LVEF 29-30\%, and whereas V-HEFT-I did not report on NYHA class, V-HEFT-II included $43 \%$ with symptoms corresponding to NYHA class III-IV. Two decades later, the African-American Heart Failure Trial (A-HEFT) [70] was conducted. The study included both men and women of African descent with symptoms corresponding to NYHA class III-IV. In this study, hydralazine and isosorbide dinitrate, as add-on to conventional HF therapy, including ACEIs, reduced total mortality and HF-related hospitalizations by $43 \%$ and $33 \%$, respectively, compared to placebo. However, it is unclear whether the results can be extrapolated to patients of other racial or ethnic origins. This is currently being tested in the Danish randomized, doubleblind, placebo-controlled trial in patients with chronic HF (DANHEART) study, which, however, does not specifically target patients with advanced HF [71]. At the current time, guidelines recommend to only consider hydralazine and isosorbide dinitrate in symptomatic HFrEF patients who do not tolerate an ACEI or ARB [23]. In patients with advanced $\mathrm{HF}$, renal dysfunction is often prevailing and hydralazineisosorbide dinitrate may be very useful here to reduce afterload and improve symptoms, e.g., during hospitalization for acute decompensated HF, where the ACEI has been held due to renal dysfunction. In contrast, if the ACEI or ARB has been held due to symptomatic hypotension, the patient is unlikely to tolerate hydralazine-isosorbide dinitrate.

\section{Diuretics and Management of Fluid Overload}

Congestion in HF patients is defined as symptoms and signs of extracellular fluid accumulation that result in increased cardiac filling pressures [72]. It is the underlying cause of $90 \%$ of HF-related hospital admissions [73, 74], and it is well documented that recurrent congestion worsens prognosis [75]. Therefore, the use of diuretics, which increase renal salt and water excretion and have some vasodilatory effects, is recommended by guidelines in congested HF patients in order to alleviate symptoms and improve exercise capacity as well as to reduce the risk of HF hospitalizations [23]. Loop diuretics, which block the sodium-potassium-chloride transporter at the ascending loop of Henle and consequently produce an intense and short diuresis, are considered as firstline therapy by guidelines in congested patients $[23,76]$. To date, no large randomized studies exist that have compared the difference between the loop diuretics furosemide, bumetanide, and torsemide. However, the Torsemide Comparison with Furosemide for Management of Heart Failure 
(TRANSFORM-HF) trial (NCT03296813) is planned to randomize 6000 hospitalized HF patients and will investigate the association of furosemide versus torsemide on all-cause mortality. Hopefully, this study will provide additional information on whether beneficial differences between the different loop diuretics exist [72]. Nonetheless, the use of loop diuretics in the HFrEF population is very common as up to $80-100 \%$ of the HFrEF patients in the large-scale chronic HF studies used loop diuretics as background therapy, and patients with advanced HF are invariably receiving diuretics [77]. Furthermore, although a mortality benefit of loop diuretics has not been proven, there is some indication from a meta-analysis of $18 \mathrm{HF}$ trials, that they might reduce the risk of death and worsening HF compared to placebo [78].

\subsection{Renal Dysfunction and Diuretic Resistance}

Decongestion is not just a goal to improve patients' symptoms, it is also a strong prognostic indicator of survival in patients with advanced HF [79]. However, the use of diuretics in this patient population poses several challenges. First, advanced HF patients often have kidney dysfunction (cardiorenal syndrome), which might be related to abnormal hemodynamics, neurohormonal activation, excessive tubular sodium reabsorption, inflammation, oxidative stress, and nephrotoxic drugs [13]. Second, loop diuretic resistance, which requires progressive dosage increases in order to achieve net fluid balance, is very common in this patient population [80]. The pathophysiology of diuretic resistance is multi-factorial and involves the activation of the sympathetic nervous system and RAAS, nephron remodeling, pre-existing renal function alterations, disrupted pharmacokinetics and dynamics of diuretics and intravascular fluid depletion due to slow plasma refilling [72]. The main driver for diuretic resistance in the kidney is tubular resistance, which involves renal blood flow, reduced proximal tubule secretion of sodium, increased sodium reabsorption in the distale tubule, and afferent arteriolar constriction [81]. Nonrenal factors contributing to diuretic resistance include, amongst others, dietary considerations. For instance, the oral bioavailability of furosemide is highly variable (10-90\%), and is determined by absorption from the gastrointestinal tract into the bloodstream, whereas the oral bioavailability for torsemide and bumetanide is consistently higher than $80-90 \%$ [72]. Consequently, food intake is of importance for the efficacy of furosemide but not torsemide or bumetanide $[82,83]$. Furthermore, although fluid and salt intake do not directly influence the efficacy of loop diuretics per se, it is difficult to overcome large amounts of fluid and salt intake $[84,85]$. In addition, since $95 \%$ of furosemide is protein bound, then low plasma albumin leads to a lower efficacy of furosemide [86]. However, evidence for the relationship between low plasma albumin and efficacy of furosemide is scarce and has only been investigated in non-HF populations [86].

\subsection{Mono- and Combination Therapy}

\subsubsection{Monotherapy}

In clinical practice, it is recommended that HFrEF patients with an inadequate response to oral loop diuretics be switched to intravenous loop diuretics starting with a dose 1- to 2-times greater than their oral dose. If proper decongestion is still not reached, as monitored by spot urinary sodium analyses (after $2 \mathrm{~h}$ ) and average urine output (after $6 \mathrm{~h}$ ), the intravenous loop diuretics should be further uptitrated by doubling the dose $[13,72]$. In HFrEF patients who have not previously received loop diuretics, the starting dose should be $\geq 20-40$ furosemide equivalents intravenously [72]. When loop diuretics are used intravenously, evidence indicates that continuous infusion of loop diuretics is more efficient than bolus therapy [87]. For instance, in the Diuretic Optimization Strategies Evaluation (DOSE) [87] study, loop diuretic administration methods were evaluated (continuous infusion vs intermittent bolus and high dose versus low dose) in 308 acute HF patients with moderate renal dysfunction, mean age $66 \pm 14$ years, and mean LVEF 35\% $\pm 18 \%$. Although no significant difference in outcomes was observed $72 \mathrm{~h}$ following treatment initiation, patients treated with a high-dose strategy tended to have greater diuresis and more decongestion compared with low-dose therapy, at the cost of transient changes in renal function [87]. Worth noting is that WRF itself, is not an independent determinant of outcomes in advanced HF patients, and that aggressive diuretic therapy, even in the setting of WRF, has been shown to positively impact survival $[88,89]$. Once the patient is stabilized, it is recommended to continue treatment with the lowest oral dose needed to keep the patient decongested [23].

\subsubsection{Combination Therapy}

In patients with diuretic resistance to monotherapy, simultanous administration of loop diuretics, such as furosemide or torsemide with thiazide diuretics, which block the electroneutral sodium-chloride transporter, or metolazone, which is a potent thiazide-like diuretic producing a diuretic response despite a low glomerular filtration rate, MRAs are recommended and are in fact considered as first-line combination therapy [72]. These agents act synergistically and provide immediate symptom relief [76, 90-94]. For instance, in one observational study [90], 21 HFrEF patients, with median age 76 (66-83) years, median LVEF 25\% (15-49), and NYHA class III or IV in $43 \%$, received a maximal dose of 5 mg metolazone on top of loop diuretics. The results showed a significant reduction in weight, $\mathrm{BP}$, plasma-sodium and 
-potassium, whereas plasma-blood urea nitrogen and -creatinine increased significantly. Furthermore, hypokalemia $(<2.5 \mathrm{mM})$ or hyponatremia $(<125 \mathrm{mM})$ were observed during $10 \%$ of the treatment episodes. In another study [91], 33 HFrEF patients in NYHA class III or IV with median age 66 (17-86) years and resistant to loop diuretics, were randomized in a $2 \times 2$ factorial design to receive bendrofluazide or metolazone on top of loop diuretics. The results showed that bendrofluazide and metolazone were equally effective in establishing a diuresis. Moreover, a fixed three-day course of the combination was as effective as a longer course. Last, in a randomized single-blind study [92] of $107 \mathrm{HFrEF}$ patients in NYHA class IV, with mean age $75 \pm 7$ years, and mean LVEF $30 \% \pm 4 \%$, it was found that small-volume hypertonic saline solution on top of high-dose furosemide was effective and well tolerated. Moreover, this treatment combination improved the QoL through the relief of signs and symptoms of congestion, and may perhaps delay more aggressive treatments. Even though the same effects were seen also in observational studies, the strategy is potentially harmful and its safety and efficacy will require demonstration in larger prospective randomized trials. Second- and third-line combination therapies involve loop diuretics combined with acetazolamide and SGLT-2 inhibitors, respectively, both of which inhibit sodium reabsorption in the proximal tubules. Several ongoing trials are investigating these combination therapies further [72]. Although effective, it is important to note that dual combination of diuretics requires close monitoring in order to avoid hypokalemia, WRF, and hypovolemia [23].

\subsection{Vasopressin Receptor Antagonists}

Vasopressin receptor antagonists (VRAs), referred to as the aquaretic agents, target the arginine vasopressin receptors and cause an increase in urine flow and the excretion of electrolyte-free water in patients with HF, without substantial changes in sodium or potassium excretion. The effects of some of the VRAs appear to be non-dose-dependent and just as effective as loop diuretics but without causing the electrolyte abnormalities and WRF that is often seen in the treatment with loop diuretics. However, the optimal use of these agents has yet to be determined, especially in patients with congestive HF. Although long-term effects on improvement in mortality have not been shown in the Efficacy of Vasopressin Antagonism in Heart Failure Outcome Study with Tolvaptan (EVEREST) trial [95], in which the selective $\mathrm{V} 2$ receptor antagonist tolvaptan was added to standard HF therapy in acute HF patients, many short-term studies indicate beneficial aquaretic and hemodynamic effects of the VRAs.

Currently, VRAs are indicated only in patients with severe hyponatremia, and although available in Europe, tolvaptan is not officially approved for HF by the European
Medicines Agency [72, 96], VRAs targeting both the V2 and the V1a receptor may have beneficial hemodynamic effects in advanced HF [97], and an oral formulation, where pecavaptan is replacing furosemide, is currently being tested in a medium-sized trial [98].

\section{Inotropic Drugs for Long-term or Intermittent Administration}

Inotropes increase cardiac output (CO) by enhancing cardiac contractility, and they also have variable vasodilatory or vasoconstrictive effects depending on the specific inotropic agent and dosage [99]. Treatment with inotropes is indicated in advanced HFrEF patients who have severely reduced $\mathrm{CO}$ resulting in end-organ dysfunction either to facilitate decongestion in refractory fluid overload, as a bridge to LVAD or HTx, or occasionally as a longer-term strategy to improve symptoms, i.e., as a palliative measure for patients without other advanced treatment options [13, 23, 99, 100]. These very specific indications for the use of inotropes are based on the fact that these agents, although beneficial on the short term with hemodynamic and consequently symptomatic improvement, have not been associated with improved outcomes, and some compounds have, in some studies, in fact worsened prognosis [13, 101-103]. For instance, in a recent systematic review and meta-analysis of 66 studies it was shown that long-term use of inotrope infusions in the ambulatory setting in advanced HFrEF improved NYHA class but did not impact survival [103]. In the following, we review the evidence for the most commonly used inotropic agents in advanced HFrEF with special emphasis on the ways of administration of inotropes (i.e., continuous vs intermittent, and high versus low dose) (Table 3 ).

\subsection{Dobutamine}

Dobutamine is a $\beta_{1}$ - and $\beta_{2}$-adrenergic receptor agonist, and causes an increase in $\mathrm{CO}$ and heart rate, and a decrease in pulmonary capillary wedge pressure (PCWP) [67]. Evidence indicates that the use of dobutamine might reduce mortality if used intermittently [104]. For instance, in one study, it was shown that long-term intermittent dobutamine infusion combined with amiodarone improved the survival of patients with advanced chronic HF refractory to conventional treatment [104]. In this study, which is considered the largest randomized, double-blind, placebo-controlled clinical trial to date investigating the long-term effects of intermittent dobutamine infusion combined with oral amiodarone, 30 patients were included with end-stage chronic HF (NYHA class IV) refractory to standard medical treatment and amiodarone, with mean age $63 \pm 9$ years, and mean LVEF $23 \%$ $\pm 5 \%$. All patients received dobutamine infusion of $10 \mu \mathrm{g} /$ 


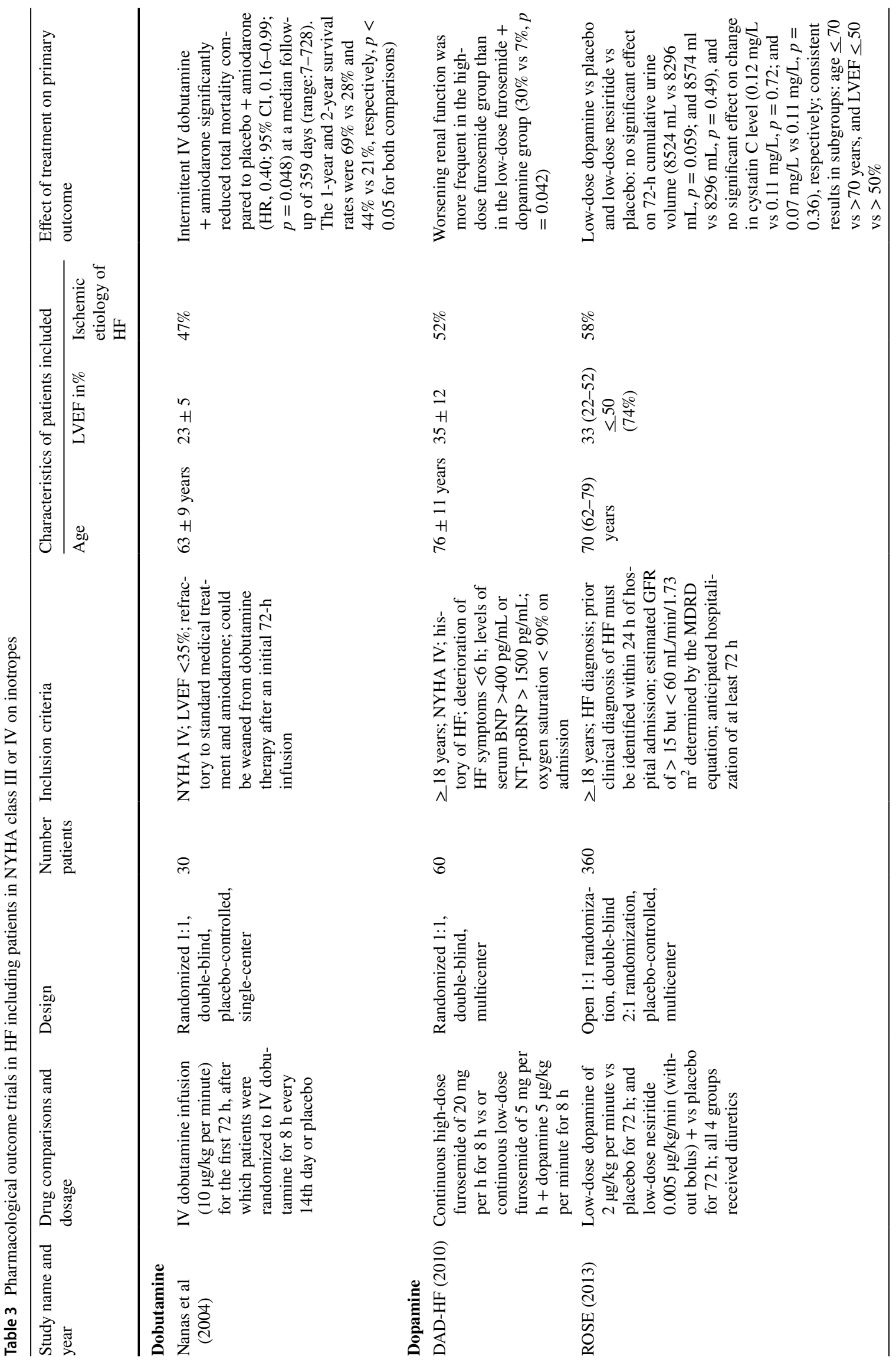




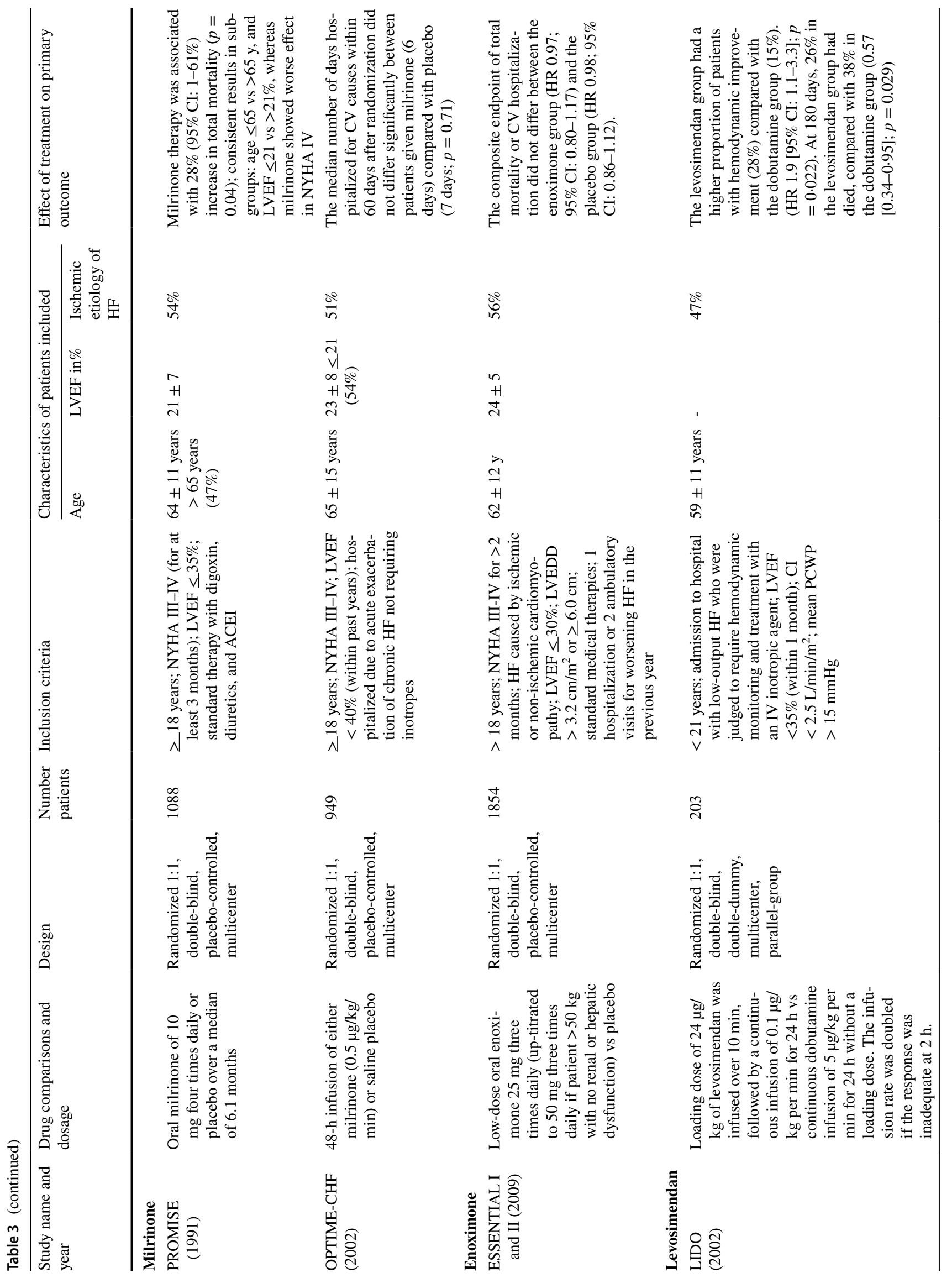




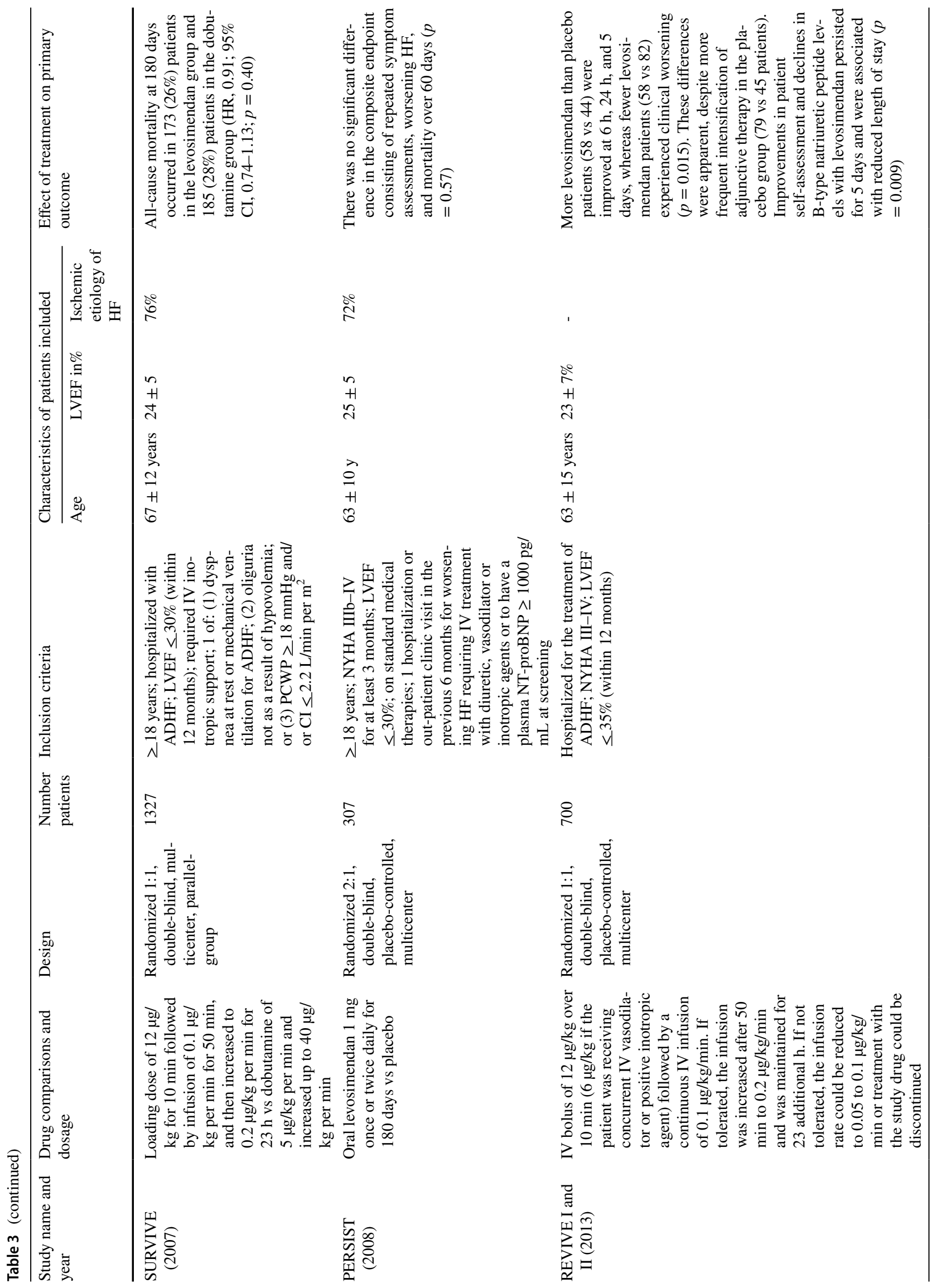




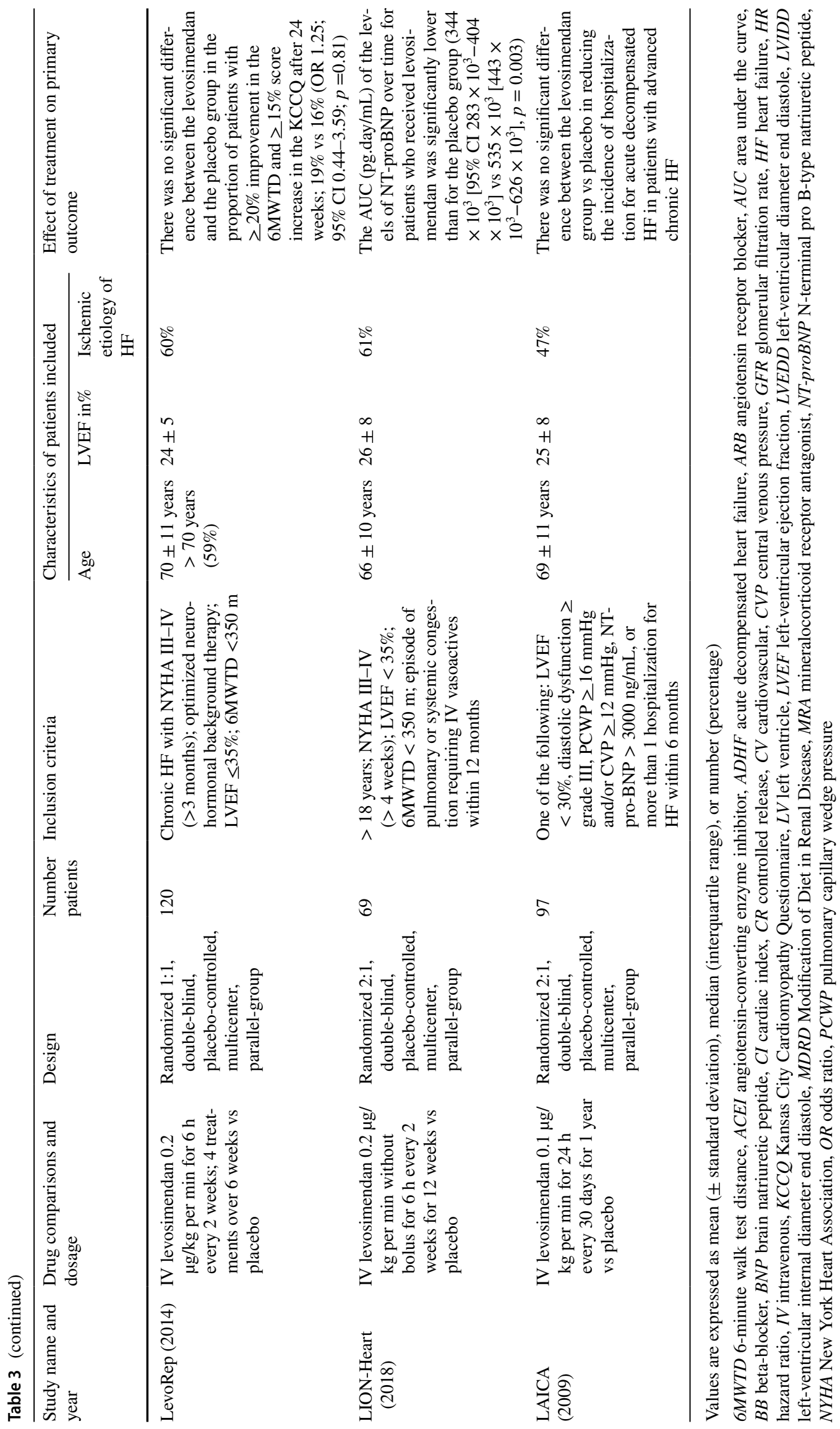


$\mathrm{kg} / \mathrm{min}$ for the first $72 \mathrm{~h}$, after which time they were either randomized 1:1 to receive intravenous dobutamine or placebo for $8 \mathrm{~h}$ every 14th day. After a median follow-up of 359 days (range: $7-728$ days), the results indicated a $60 \%$ reduction in the risk of death from any cause in the group treated with the combination of dobutamine and amiodarone, compared with the group treated with placebo and amiodarone ( $p=0.048)$. Other studies exploring the association between dobutamine and mortality have suggested that the increased risk of mortality might be related to prolonged infusions and/or the administration of relatively high doses of dobutamine $[105,106]$.

In terms of symptomatic relief, both continuous as well as intermittent use of dobutamine has been shown to improve symptoms. For instance, in a retrospecive study [107], 21 patients with palliative end-stage HF, mean age $77 \pm 9$ years, were discharged with continuous intravenous home dobutamine of $4 \mu \mathrm{g} / \mathrm{kg} / \mathrm{min}$ (for a person weighing $80 \mathrm{~kg}$ ). Six weeks after the initiation of dobutamine, patients had a significant improvement in NYHA class and global assessment scale (both $p<0.001)$ as well as NT-proBNP (6247 vs $2543 \mathrm{pg} / \mathrm{mL} ; p=0.03$ ). Consistantly, in another study, which investigated the QoL in 287 patients with advanced refractory HF symptoms (NYHA class III-IV), mean age $68 \pm 12$ years, and mean LVEF $26 \% \pm 13 \%$, the patients were treated with low-dose, intravenous intermittent dobutamine therapy ( $3 \mu \mathrm{g} / \mathrm{kg} / \mathrm{min}$ ) in an outpatient setting 1-2 times a week [108]. Dopamine 1-3 $\mu \mathrm{g} / \mathrm{kg} / \mathrm{min}$ was given for dobutamine intolerance and to patients with advanced renal failure and inadequate urinary response. The results indicated an overall improvement in QoL associated with intermittent low-dose dobutamine therapy $(p<0.01)$. Interestingly, multivariate analysis showed that younger age, non-ischemic cardiomyopathy, and worse renal function were independently associated with improvement in QoL at 1 year.

\subsection{Dopamine}

Dopamine is an endogenous catecholamine that, at low doses $(\leq 3 \mu \mathrm{g} / \mathrm{kg} / \mathrm{min})$, may selectively activate dopamine receptors and promote renal vasodilatation [109]. There are no dedicated trials of dopamine in chronic advanced HF, but two trials tested the effect of low-dose dopamine in hospitalized patients with decompensated HF on renal function and diuresis. The Dopamine in Acute Decompensated Heart Failure (DAD-HF) trial included 60 patients with mean age $76 \pm 11$ years and mean LVEF $35 \% \pm 12 \%$, could not demonstrate an effect of low-dose dopamine combined with low-dose furosemide compared with high-dose furosemide alone on renal function, diuresis, or CV events [110]. The larger Renal Optimization Strategies Evaluation (ROSE) trial included 360 patients with median age $70(62-79)$ years and median LVEF 33\% (22-52), did not demonstrate any effect of dopamine on diuresis or cystatin C levels compared with placebo [111]. Taken together, the previously postulated concept of "renal-protective" dopamine in advanced or acute decompensated HF has not been confirmed in clinical trials. Consequently, dopamine has no primary role in the treatment of advanced HF irrespectve of renal function.

\subsection{Milrinone}

Milrinone is a phosphodiesterase (PDE) inhibitor, with both inotropic and vasodilator properties, which increase $\mathrm{CO}$ and reduce systemic vascular resistance and PCWP. It has hemodynamic effects similar to dobutamine but is associated with less tachycardia [112]. In the Prospective Randomized Milrinone Survival Evaluation (PROMISE) [113] study, there was no beneficial effect of milrinone on mortality. In this trial, 1088 chronic HF patients with NYHA class III-IV despite conventional therapy, with mean age 64 \pm 11 years, and mean LVEF $21 \% \pm 7 \%$, were randomized to oral milrinone of $10 \mathrm{mg}$ four times daily or placebo over a median follow-up period of 6.1 months. The results showed that milrinone therapy was associated with a $28 \%$ (95\% CI: $1-61 \%)$ increase in total mortality $(p=0.04)$ and a $34 \%$ (95\% CI: 6-69\%) increase in CV mortality $(p=0.02)$. Consistent results were found in the subgroups age $<65$ versus $>65$ years and LVEF $<21 \%$ versus $>21 \%$, whereas milrinone showed worse effect in NYHA IV. Interestingly, the beneficial effects of milrinone might then be related to certain sub-groups only. This view was further supported by the Outcomes of a Prospective Trial of Intravenous Milrinone for Exacerbations of Chronic Heart Failure (OPTIME-CHF) study [114]. A total of 949 chronic HF patients, with mean age $65 \pm 15$ years, mean LVEF $23 \% \pm 8 \%$, and $92 \%$ in NYHA class III-IV, were hospitalized due to an exacerbation of chronic HF and randomized to a 48-h infusion of either milrinone $(0.5 \mu \mathrm{g} / \mathrm{kg} / \mathrm{min})$ or saline placebo. The main result, which was the median number of days hospitalized for $\mathrm{CV}$ causes within 60 days after randomization, did not differ significantly between patients given milrinone (6 days) compared with placebo ( 7 days; $p=0.71$ ). In addition, milrinone was not significantly associated with in-hospital mortality or 2 -month mortality (3.8\% vs $2.3 \%$ and $10.3 \%$ vs $8.9 \%$, respectively), nor did the composite endpoint of death or readmission differ between the two groups. Rather, milrinone therapy was associated with increased hypotensive episodes and arrhythmias. However, in a sub-group analysis, where the results were stratified by ischemic and non-ischemic cardiomyopathy, milrinone-treated patients with ischemic etiology tended to have worse outcomes than those treated with placebo in terms of the primary end point (13.6 days for milrinone vs 12.4 days for placebo, $p=0.055$ for interaction) and the composite of death or rehospitalization ( $42 \%$ vs $36 \%$ for placebo, $p=0.01$ for interaction). 
In contrast, outcomes in non-ischemic patients treated with milrinone tended to be improved in terms of the primary end point (10.9 vs 12.6 days placebo) and the composite of death or rehospitalization ( $28 \%$ vs $35 \%$ placebo) [115]. The role of milrinone in advanced HF is not fully elucidated but the concept of oral milrinone, now in an extended-release formulation, is being revitalized in recent small and ongoing trials [116].

\subsection{Enoximone}

Enoximone is a type III PDE inhibitor with positive inotropic and vasodilator properties [117]. It has been investigated in the Studies of Oral Enoximone Therapy in Advanced HF (ESSENTIAL I and II) [118], which consisted of two identical, randomized, double-blind, placebo-controlled trials that differed only by geographic location (North and South America [Essential-I; Europe: Essential-II]). These two trials investigated the effects of low doses of enoximone on symptoms, exercise capacity, and major clinical outcomes in patients with advanced HF who were also treated with BBs and other guideline-recommended background therapy. A total of 1854 patients, all in NYHA class III-IV, mean age $62 \pm 12$ years, and mean LVEF $24 \% \pm 5 \%$, were randomized to enoximone $25 \mathrm{mg}$ three times daily or placebo. The composite endpoint of total mortality or CV hospitalization did not differ between the enoximone group (HR 0.97; 95\% CI: $0.80-1.17 \%$ ) and the placebo group (HR 0.98; 95\% CI: $0.86-1.12 \%$ ). Thus, although low-dose enoximone appeared to be safe in patients with advanced HF, major clinical outcomes were not improved.

\subsection{Levosimendan}

Levosimendan is a calcium sensitizer which causes $\mathrm{CO}$ enhancement (systolic and diastolic function) without increasing myocardial oxygen demand, vasodilatation leading to increased peripheral perfusion, decreased PCWP, and reduced neurohormone levels, such as BNP [67, 119]. A recent meta-analysis of 50 randomized clinical trials in over 6000 patients, including acutely decompensated as well as advanced chronic HF patients, amongst others, demonstrated a reduction in mortality with levosimendan $[67,120]$.

In comparison to dobutamine, the beneficial effects of levosimendan has been shown to be superior in some but not all trials. For instance, in the randomized, double-blind, double-dummy parallel-group trial, Levosimendan Infusion versus Dobutamine (LIDO) [119], 203 patients hospitalized with severe chronic or acute HF (all NYHA III-IV), and with mean age $59 \pm 11$ years, either received intravenous levosimendan starting with a loading dose of $24 \mu \mathrm{g} / \mathrm{kg}$ infused over $10 \mathrm{~min}$, followed by a continuous infusion of $0.1 \mu \mathrm{g} /$ $\mathrm{kg} / \mathrm{min}$ for $24 \mathrm{~h}$, or dobutamine, which was infused for $24 \mathrm{~h}$ at an initial dose of $5 \mu \mathrm{g} / \mathrm{kg} / \mathrm{min}$ without a loading dose. The infusion rate was doubled if the response was inadequate at 2 h. The primary endpoint was the proportion of patients with hemodynamic improvement (defined as an increase of $30 \%$ or more in CO and a decrease of $25 \%$ or more in PCWP) at $24 \mathrm{~h}$, and it was achieved in $29(28 \%)$ patients in the levosimendan group and $15(15 \%)$ in the dobutamine group (HR 1.9 [95\% CI: $1.1-3.3] ; p=0.022)$. At 180 days, $27(26 \%)$ patients in the levosimendan group had died, compared with $38(38 \%)$ in the dobutamine group $(0.57$ [0.34-0.95]; $p=$ 0.029). However, in contrast, the randomized, double-blind Survival of Patients With Acute Heart Failure in Need of Intravenous Inotropic Support (SURVIVE) [121] study compared the effect of short-term intravenous infusion of levosimendan or dobutamine on long-term survival in 1327 patients hospitalized with acute decompensated HF (NYHA class III-IV) who required inotropic support. These patients had mean age of $67 \pm 12$ years, mean LVEF $24 \% \pm 5 \%$, and received either levosimendan (loading of $12 \mu \mathrm{g} / \mathrm{kg}$ for 10 minutes, followed by infusion of $0.1 \mu \mathrm{g} / \mathrm{kg} / \mathrm{min}$ for $50 \mathrm{~min}$ utes; and increased to $0.2 \mu \mathrm{g} / \mathrm{kg} / \mathrm{min}$ for $23 \mathrm{~h}$ ) or dobutamine ( $5 \mu \mathrm{g} / \mathrm{kg} / \mathrm{min}$ and increased up to $40 \mu \mathrm{g} / \mathrm{kg}$ per minute). The results showed that all-cause mortality at 180 days occurred in $173(26 \%)$ patients in the levosimendan group and in 185 (28\%) patients in the dobutamine group (HR, 0.91; 95\% CI, $0.74-1.13 ; p=0.40)$. From the LIDO and SURVIVE trials, it appears that, especially in hospitalized advanced HFrEF patients, continuous levosimendan might have a beneficial hemodynamic and mortality reducing effect compared to dobutamine.

Moreover, there is some indication that continuous levosimendan provides rapid and durable symptomatic relief [122, 123]. For example, in the Randomized Evaluation of Intravenous Levosimendan Efficacy (REVIVE I and II) [122] study, 700 patients, with a mean age of $63 \pm 15$ years and mean LVEF $23 \% \pm 7 \%$, admitted with acute decompensated $\mathrm{HF}$ received intravenous levosimendan or placebo for $24 \mathrm{~h}$ in addition to standard treatment. More patients in the levosimendan group ( $n=58)$ compared to the placebo group ( $n$ $=44$ ) had improved clinical status at $6 \mathrm{~h}, 24 \mathrm{~h}$, and 5 days after randomization. In addition, fewer patients in the levosimendan group $(n=58)$ compared to the placebo group $(n=$ 82 ) experienced clinical worsening ( $p=0.015$ for the difference between the groups). These differences were apparent, despite more frequent intensification of adjunctive therapy in the placebo group (79 vs 45 patients). Improvements in patient self-assessment and reduction in BNP levels with levosimendan persisted for 5 days and were associated with a reduced length of stay $(p=0.009)$. Consistently, another study using continuous oral levosimendan of 1 or $2 \mathrm{mg}$ daily for 180 days versus placebo in 307 NYHA IIIb-IV advanced HFrEF patients showed improved QoL and decreased NTproBNP [124]. 
In more recent years, intermittent ambulatory treatment with levosimendan has been investigated in patients with advanced HF in order to elucidate potiential improvements in outcomes such as functional capacity, QoL, and event-free survival. For instance, in the pulsed infusions of Levosimendan in Outpatients with Advanced Heart Failure (LevoRep) [125] study, 120 NYHA III-IV outpatients with advanced $\mathrm{HF}$, mean age $70 \pm 11$ years and mean LVEF $24 \%$ $\pm 5 \%$, received either infusion of levosimendan $0.2 \mu \mathrm{g} / \mathrm{kg} /$ min or placebo for $6 \mathrm{~h}$ every 2 weeks over a total period of 6 weeks, in addition to standard care therapy. There was no significant difference between the groups in the proportion of patients with $\geq 20 \%$ improvement in the 6-minute walk test distance (6MWTD) and $\geq 15 \%$ score increase on the Kansas City Cardiomyopathy Questionnaire (KCCQ) at the end of the 24-week study period (19\% in the levosimendan group vs $15.8 \%$ in the placebo group; $p=0.81)$. However, interestingly, there was a trend towards better survival as cardiac death (4 vs 1), HTx (2 vs 1), and acute HF (14 vs 9) were more frequent in the placebo group as compared to the levosimendan group. Moreover, the incidence of side effects was comparable between the two groups. In contrast, a similar although smaller trial $(n=69)$, the Levosimendan Intermittent administration in Outpatients: effects on Natriuretic peptides in advanced chronic HEART failure (LION-HEART) [126], showed that intermittent administration of levosimendan compared to placebo in ambulatory patients with advanced HFrEF reduced plasma concentrations of NT-proBNP, worsening of health-releated QoL, and hospitalisation for HF. Adverse event rates, however, were similar in the two treatment groups. The characterisics of the patients included in the LION-HEART trial were similar to the LevoRep trial, and although the dose of intravenous levosimendan was similar in both trials, the protocol of the LION-HEART trial had an additional 2 cycles of intravenous levosimendan therapy. In another trial, the Effects of Intermittent Repeated Levosimendan Administration in patients with Advanced HF (LAICA) [127], 97 patients all in NYHA III-IV, mean age $69 \pm 11$ years, and mean LVEF $25 \% \pm 8 \%$, received either levosimendan of $0.1 \mu \mathrm{g} / \mathrm{kg} / \mathrm{min}$ for $24 \mathrm{~h}$ every 30 days or placebo for a year in addition to optimal medical therapy. Levosimendan did not reduce the incidence of hospitalization for acute decompensated HF. However, the results favored levosimendan both in terms of fewer admissions for acute decompensated HF and in terms of lower mortality rates. The rate of adverse events was comparable between levosimendan and placebo.

Differences among the various trials make it difficult to draw any firm conclusions; nevertheless, repetitive infusions of levosimendan have demonstrated safety and several benefits in terms of improved hemodynamics, symptoms, re-hospitalization rates, and biomarkers [128]. In fact, two recent meta-analyses indicate that intermittent levosimendan administration in advanced HF is associated with a significant reduction in mortality at the longest follow-up available [129], as well as in the rehospitalization rate at 3 months [130]. However, these meta-analyses included several heterogenous small trials of a repeated infusion strategy, and therefore more robust data are needed on hospitalization and mortality rates associated with repetitive use of levosimendan [131]. The ongoing levosimendan infusions for patients with advanced chronic heart failure (LeoDOR) [132] trial, tests the hypothesis that repetitive levosimendan infusions ( 6 or $24 \mathrm{~h}$ ) for 12 weeks versus placebo, in addition to optimized standard therapy, in patients following hospitalization for acute HF, will improve outcomes in advanced HF patients with persistent NYHA III symptoms or high BNP after a HF hospitalization

\section{New Drugs}

Several newer drugs have shown beneficial effects in patients with HFrEF and more advanced symptoms [67]. Omecamtiv mecarbil, a cardiac myosin activator, directly improves cardiac function by increasing systolic ejection time without increasing ventricular contractility (dp/dt) so that myocardial oxygen consumption remains constant. Recent trials have shown favorable results, including decreased ventricular dimensions and volumes, increased stroke volume and ejection fraction (EF), and reduced heart rate and NT-proBNP concentrations [133], improved health-related QoL [134], as well as a reduction in the composite of a HF-related event or death from CV causes in the Global Approach to Lowering Adverse Cardiac Outcomes Through Improving Contractility in Heart Failure (GALACTIC-HF) randomized clinical trial [135]. The effect was particularly prominent in patients with lower LVEF [135, 136]. Consistently, an analysis focused on 2258 patients with severe HF, defined similarly to the HFA criteria, as with NYHA symptom class III to IV, LVEF $\leq$ $30 \%$, and with a HF hospitalization within the previous 6 months enrolled in GALACTIC-HF, showed a highly significant treatment effect of omecamtiv mecarbil on the primary endpoint of cardiovascular death or HF hospitalizations (HR, $0.80 ; 95 \%$ CIs, 0.71-0.90) [18].

Vericiguat, a soluble guanylate cyclase stimulator, which acts by augmenting nitric oxide production, has been shown to reduce the incidence of death from $\mathrm{CV}$ causes or hospitalization for HF in patients admitted with HF, or recently discharged [137]. However, contrary to that observed with omecamtiv mecarbil, the beneficial effects of vericiguat on outcome were shown only in patients in the three lower quartiles of NT-proBNP levels at baseline, which suggests that this drug may be less effective in patients with more advanced HF [138]. 
Taken together, inotropes generally improve symptoms in advanced HFrEF patients, and more recent studies using newer drugs indicate a trend towards better survival. Intermittent levosimendan treatment also improves symptoms; however, it has not yet been shown to improve survival in a dedicated trial. New drugs appear promising and could play an important role in the treatment of advanced HFrEF patients. In clinical practice, inotropes should only be used when clinical signs of low $\mathrm{CO}$ or high filling pressures persist, despite the use of conventional therapy, and when there is end-organ dysfunction. A clear goal should be stated prior to the initiation of inotropes, such as bridge to improvement and oral guideline-directed medical therapy, bridge to mechanical circulatory support (MCS)/HTx, or palliation. The length of the evaluation period as well as when to reevaluate should be clearly stated. Optimal timing and use of inotropes require further study.

\section{Use of HF Drugs in Durable Mechanical Circulatory Support}

An increasing number of advanced HFrEF patients are living with a continuous-flow (CF) LVAD, most commonly as a bridge to HTx or destination therapy. Thus, an increasing support duration has been reported due to the advancements in LVAD technology along with the limited number of donor organs [139]. Currently, 2-year survival rates of LVAD patients are $\sim 80 \%$, which is comparable to HTx [140]. Consequently, most LVAD recipients, including those with bridge to HTx, remain on LVAD for a longer period of time. For instance, in the Evaluating the HeartMate $3^{\mathrm{TM}}$ with Full MagLev Technology in a Post-Market Approval Setting (ELEVATE) trial, only $9 \%$ of HeartMate $3^{\mathrm{TM}}$ patients received a HTx after 2 years [141]. As patients are living longer with a CF-LVAD, it is of utmost importance to optimize LVAD support of the circulatory system in order to avoid LVAD recurrence of HF symptoms, especially if there is no $\mathrm{LV}$ recovery, as well as complications such as pump dysfunction, stroke, aortic regurgitation (AR), ventricular arrhythmias, and right ventricular (RV) failure, amongst others [142]. Below describes the use of HF drugs in relation to lowering risk of complications as well as improving myocardial recovery in CF-LVAD recipients.

\subsection{Blood Pressure Regulation}

As the LVAD pump is afterload dependent, it is crucial to manage BP since uncontrolled hypertension can lead to decreased LVAD flow and less effective LV unloading, resulting in complications such as increased risk of stroke and decreased frequency of aortic valve opening leading to aortic regurgitation (AR) [143-147]. In previous studies, the incidence of stroke was reported to be $17 \%$ at 2 years [148], but recently a considerably lower risk has been reported with the Heartmate 3 device [149]. The incidence of AR varies from $10 \%$ to $53 \%$, depending on the study [142]. In one study, investigating the association between high BP and risk of stroke [143], 275 LVAD recipients were divided into either of two groups depending on whether their systolic $\mathrm{BP}$ (SBP) w above or below a median of $100 \mathrm{mmHg}$ during the last $48 \mathrm{~h}$ prior to discharge from implantation hospitalization. Whereas the above-median SBP group had a mean SBP of $110 \mathrm{mmHg}$, the below-median SBP group had a mean SBP of $95 \mathrm{mmHg}$. The results showed that during a mean follow-up of 16 months, stroke occurred in $16 \%$ of the above-median SBP group versus 7\% in the below-median SBP group (hazard ratio [HR] 2.38, 95\% CI 1.11-5.11), with a similar proportion of hemorrhagic and ischemic strokes in each group. In another study [146], 48 of 90 (53\%) CFLVAD recipients developed de novo $\mathrm{AR}$ ( $\geq$ mild $\mathrm{AR}$ ) following CF-LVAD implantation over a duration of 575 days (range 98-2433 days). Serial readings of SBP and diastolic blood pressure (DBP) as well as the mean arterial pressure (MAP) obtained post-operatively at fixed time-intervals indicated that the AR group had significantly higher BP than the non-AR group at 3 months (SBP, $100 \mathrm{mmHg}$ vs $93 \mathrm{mmHg}$, $p=0.038$; DBP, $82 \mathrm{mmHg}$ vs $66 \mathrm{mmHg}, p<0.001$; and MAP, $87 \mathrm{mmHg}$ vs $74 \mathrm{mmHg}, p<0.001$ ) and at 6 months (DBP, $73 \mathrm{mmHg}$ vs $62 \mathrm{mmHg}, p=0.044$; MAP, $83 \mathrm{mmHg}$ vs $75 \mathrm{mmHg}, p=0.049$ ), respectively. In addition, SBP at 3 months was an independent predictor of AR following CF-LVAD implantation (OR 1.004, 95\% CI 1.000-1.009, $p=0.04)$.

In practice, to lower BP, the 2019 European Association for Cardio Thoracic Surgery (EACTS) expert consensus on long-term MCS recommends a MAP $<85 \mathrm{mmHg}$ for CF-LVADs [142]. As conventional measurement of BP is somewhat difficult, it is common practice to use a Doppler $\mathrm{BP}$ reading as the mean systemic BP [150]. ACEIs or ARBs are recommended as first-line drugs for CF-LVAD hypertension. BBs can be used in combination with ACEIs or ARBs but caution should be exercised in patients with marginal RV function. Furthermore, calcium antagonists, especially the dihydropyridines, can be used as a third option. MRAs (spironolactone) should be used for their potassium-sparing and antifibrotic effects [142]. Hydralazine and perhaps ARNI [151-153] are other options of BP-lowering drugs that can be considered in CF-LVAD recipients with hypertension. Evidence indicates that BP control can be achieved in patients with CF-LVADs, with the majority of patients requiring only 1 or 2 antihypertensives [154]. In addition, most LVAD recipients also require diuretics due to volume overload, and these agents also lower BP [155]. It is important to closely monitor the diuretic dose to ensure relief of fluid overload and to avoid depletion of intravascular 
volume, which could result in suction events, pump alarms, arrhythmias, and syncope.

\subsection{Chronic Right Heart Failure}

Chronic right $\mathrm{HF}$ is seen in 10\%-15\% of patients after LVAD implant, and it entails typical signs and symptoms of volume overload such as edema, weight gain, ascites, and jugular venous distension. Although currently there is no consensus about the definition of chronic right HF, previous work has used definitions of chronic right HF on occasions such as the need for inotropic support or right ventricular assist device (RVAD) implantation 14 days after surgery, or as rehospitalization after index hospital discharge and medical or surgical treatments, including strengthening of diuretics, inotropic support and RVAD implantation [156-158]. Studies have shown that LVAD recipients who develop chronic right HF after LVAD implant have a worse prognosis [157, 159]. For instance, in one study of $141 \mathrm{HF}$ patients, mean age $53 \pm 13$ years and mean LVEF $16 \pm 7 \%$, with LVAD as a bridge to HTx, chronic right HF developed in $12(15 \%)$ patients during LVAD support. The 5-year post-HTx survival was significantly worse in those patients who developed chronic right HF during LVAD support compared with patients who did not develop chronic right HF (26\% vs $87 \%, p<0.0001$ ) [157]. It is recommended that LVAD recipients who develop chronic right HF be treated with diuretics, as well as ACEIs, $\mathrm{BBs}$, and MRAs (spironolactone); however, the evidence for this is rather scarce [142]. Interestingly, a recent proof of concept study investigated the safety of oral milrinone as a treatment option in LVAD recipients with severe right HF [160]. In this study, 6 stable LVAD recipients with mean age 63 years, and who were at least 30 days post-implant, developed chronic right HF defined by echocardiography and confirmed by right heart catheterization with right atrial pressure $\geq 12 \mathrm{mmHg}$ despite diuretic therapy. The results indicated that although right atrial pressure, pulmonary artery pressure, and PCWP did not change significantly, $\mathrm{CO}$ improved from $3.9 \pm 0.6$ to $5.8 \pm 1.9 \mathrm{~L} / \mathrm{min}(p=0.036)$, and consequently, pulmonary vascular resistance and systemic vascular resistance both decreased significantly. RV stroke work index also improved as did the QoL measured by $\operatorname{KCCQ}(p=0.041)$.

\subsection{Myocardial Recovery}

Myocardial recovery in LVAD recipients refers to the significant improvement of the LV function as a consequence of the mechanical unloading by the LVAD [161], and in larger series $1 \%-5 \%$ of implanted patients, the $\mathrm{LV}$ recovers to a degree that allows for explant of the device $[162,163]$. Myocardial recovery most often occurs in younger patients, with shorter duration of disease, as well as in those with
HF etiologies such as myocarditis and dilated- and peripartum-cardiomyopathy [164]. The 2019 EACTS expert consensus on long-term MCS [142] recommends continuation and optimization of medical HF therapy and neurohumoral blockage in potential recovery candidates. Moreover, it is recommended that all patients with non-ischemic cardiomyopathy be treated as potential bridge-to-recovery candidates. To date, no randomized clinical trials on the effect of neurohormonal blockage in relation to myocardial recovery in LVAD recipients exist; however, some evidence indicates that aggressive HFrEF therapy might be beneficial in myocardial recovery [165-167]. For instance, in the Remission from Stage D Heart Failure (RESTAGE-HF) [165] study, myocardial recovery was investigated in LVAD recipients who received an aggressive pharmacological regimen to enhance reverse remodeling. In this study, 40 advanced HF patients with non-ischemic cardiomyopathy, and mean age $35 \pm 11$ years, received the HeartMate II LVAD, and LVAD speed was optimized with an aggressive pharmacological regimen based on the Harefield protocol [166] consisting of 5 drugs (ACEI, ARB, BB, MRA [spironolactone], and digoxin), which were initiated immediately after the weaning of inotropic support after the LVAD implant and uptitrated to a MAP $>60 \mathrm{mmHg}$, as long as the patient was asymptomatic with adequate renal function and electrolytes within the normal range. The study demonstrated that $40 \%$ (36/40) of patients achieved the primary endpoint of sufficient improvement of myocardial function to reach criteria for explantation within 18 months with sustained remission from HF (freedom from HTx, VAD, death) at 12 months ( $p<0.0001)$, with 50\% (18/36) of patients receiving the protocol being explanted within 18 months. Overall, 52\% (19/36) were explanted of those receiving the protocol. After explantation, survival free from LVAD or HTx was $90 \%$ at Year 1, and $77 \%$ at Years 2 and 3. In clinical practice, after CF-LVAD explant for myocardial recovery, patients should receive lifelong treatment by HF specialists to target medical therapy and identify recurrence of HF. Moreover, even in those patients where LV recovery is insufficient to warrant LVAD explant, the cardiac improvement by HFrEF drugs may still provide clinical benefit for the patients [168].

\section{Conclusions and Future Perspectives}

This review has provided an overview of currently available therapeutic options for patients with advanced HFrEF, as well as suggestions on how to manage guideline-directed therapy in this patient group. Altogether, advanced HFrEF patients benefit from contemporary guideline-directed HF drugs, and data for newer treatments such as SGLT-2 inhibitors, intravenous ferric caboxymaltose, and omecamtiv mecarbil are still accumulating. In addition, diuretics are 
usually indicated in most advanced HFrEF patients, often as combination therapy due to renal dysfunction and diuretic reisistance. Inotropes should be considered only in those patients who have persistent clinical signs of low $\mathrm{CO}$ or high filling pressures despite the use of conventional therapy, be it as a bridge to MCS, HTx, or palliation. Lastly, the role of HFrEF drugs is important in LVAD recipients in relation to lowering the risk of complications as well as for improving myocardial recovery. Ongoing studies, specifically targeting the advanced HFrEF population, will elucidate whether the newer HFrEF drugs as well as intermittent use of inotropes in both in- and out-patient settings, will have a role in this patient population.

\section{Declarations}

Funding No external funds were userd in the preparation of this invited manuscript.

Conflicts of interest FG reports consulting fees from Abbott, Pfizer, Bayer, Ionis, Alnylam, Boehringer-Ingelheim, and speakers fees from Novartis, AstaZeneca, Orion Pharma. MM reports consulting fees from Actelion, Amgen, Astra-Zeneca, Abbott vascular, Bayer, Servier, Edwards Therapeutics, Livanova, Vifor pharma, WindTree Therapeutics, as member of Trials' Committees or Advisory Boards or for speeches at sponsored meetings in the last three years.

Author contributions Manuscript was written by JV, FG, DT, and MM. All the authors have participated to enhance the quality of the paper. All of them met the International Committee of Medical Journal Editors (ICMJE) criteria for authorship of this paper, take the full responsibility for the integrity of the work as a whole, and have given their approval for this final version to be published.

Ethics approval This article is based on previously conducted studies and does not contain any studies with human participants or animal performed by the authors without a previous Ethics Committee approval.

Consent to participate and consent to publish All the authors have contributed to review and enhancement of the quality of the paper and have reviewed and approved the final draft of the manuscript.

\section{Availability of data and material Not applicable.}

Code availability Not applicable.

Open Access This article is licensed under a Creative Commons Attribution-NonCommercial 4.0 International License, which permits any non-commercial use, sharing, adaptation, distribution and reproduction in any medium or format, as long as you give appropriate credit to the original author(s) and the source, provide a link to the Creative Commons licence, and indicate if changes were made. The images or other third party material in this article are included in the article's Creative Commons licence, unless indicated otherwise in a credit line to the material. If material is not included in the article's Creative Commons licence and your intended use is not permitted by statutory regulation or exceeds the permitted use, you will need to obtain permission directly from the copyright holder. To view a copy of this licence, visit http://creativecommons.org/licenses/by-nc/4.0/.

\section{References}

1. Results of the Cooperative North Scandinavian Enalapril Survival Study (CONSENSUS). Effects of ealapril on mortality in severe congestive heart failure. NEJM. 1987;316:1429-35.

2. The SOLVD Investigators. Effect of enalapril on survival in patients with reduced left ventricular ejection fractions and congestive heart failure. NEJM. 1991;325:293-302.

3. Cohn J, Tognoni G. For the Valsartan Heart Failure Trial Investigators. A randomized trial of the angiotensin-receptor blocker valsartan in chronic heart failure. NEJM. 2001;345:1667-75.

4. CIBIS-II Investigators and Committees. The cardiac insufficiency bisoprolol study II (CIBIS-II): a randomised trial. Lancet. 1999;353:9-13.

5. Pitt B, Zannad F, Remme W, Cody R, Castaigne A, Perez A, Palensky J, Wittes J. For the randomized aldactone evaluation study investigators. The effect of spironolactone on morbidity and mortality in patients with severe heart failure. NEJM. 1999;341:709-17.

6. McMurray JJ, Packer M, Desai AS, Gong J, Lefkowitz MP, Rizkala AR, Rouleau JL, Shi VC, Solomon SD, Swedberg K, Zile $\mathrm{MR}$, Investigators P-H and Committees. Angiotensin-neprilysin inhibition versus enalapril in heart failure. N Engl J Med. 2014;371:993-1004.

7. McMurray JJV, Solomon SD, Inzucchi SE, Kober L, Kosiborod MN, Martinez FA, Ponikowski P, Sabatine MS, Anand IS, Belohlavek J, Bohm M, Chiang CE, Chopra VK, de Boer RA, Desai AS, Diez M, Drozdz J, Dukat A, Ge J, Howlett JG, Katova T, Kitakaze M, Ljungman CEA, Merkely B, Nicolau JC, O’Meara E, Petrie MC, Vinh PN, Schou M, Tereshchenko S, Verma S, Held C, DeMets DL, Docherty KF, Jhund PS, Bengtsson O, Sjostrand M, Langkilde AM, Committees D-HT and Investigators. Dapagliflozin in patients with heart failure and reduced ejection fraction. N Engl J Med. 2019;381:1995-2008.

8. Packer M, Anker SD, Butler J, Filippatos G, Pocock SJ, Carson P, Januzzi J, Verma S, Tsutsui H, Brueckmann M, Jamal W, Kimura K, Schnee J, Zeller C, Cotton D, Bocchi E, Bohm M, Choi DJ, Chopra V, Chuquiure E, Giannetti N, Janssens S, Zhang J, Gonzalez Juanatey JR, Kaul S, Brunner-La Rocca HP, Merkely B, Nicholls SJ, Perrone S, Pina I, Ponikowski P, Sattar N, Senni M, Seronde MF, Spinar J, Squire I, Taddei S, Wanner C, Zannad F, Investigators EM-RT. Cardiovascular and renal outcomes with empagliflozin in heart failure. N Engl J Med. 2020;383:1413-24.

9. GBD 2017 Disease and Injury Incidence and Prevalence Collaborators. Global, regional, and national incidence, prevalence, and years lived with disability for 354 diseases and injuries for 195 countries and territories, 1990-2017: a systematic analysis for the global burden of disease study 2017. The Lancet. 2018;392:1789-1858.

10. Kalogeropoulos AP, Samman-Tahhan A, Hedley JS, McCue AA, Bjork JB, Markham DW, Bhatt KN, Georgiopoulou VV, Smith AL, Butler J. Progression to stage D heart failure among outpatients with stage $\mathrm{C}$ heart failure and reduced ejection fraction. JACC Heart Fail. 2017;5:528-37.

11. Metra M, Ponikowski P, Dickstein K, McMurray JJ, Gavazzi A, Bergh CH, Fraser AG, Jaarsma T, Pitsis A, Mohacsi P, Bohm M, Anker S, Dargie H, Brutsaert D, Komajda M, Heart Failure Association of the European Society of C. Advanced chronic heart failure: a position statement from the study group on advanced heart failure of the heart failure association of the European society of cardiology. Eur J Heart Fail. 2007;9:684-94.

12. Fang JC, Ewald GA, Allen LA, Butler J, Westlake Canary CA, Colvin-Adams M, Dickinson MG, Levy P, Stough WG, Sweitzer NK, Teerlink JR, Whellan DJ, Albert NM, Krishnamani R, Rich MW, Walsh MN, Bonnell MR, Carson PE, Chan MC, Dries DL, 
Hernandez AF, Hershberger RE, Katz SD, Moore S, Rodgers JE, Rogers JG, Vest AR, Givertz MM, Heart Failure Society of America Guidelines C. Advanced (Stage D) heart failure: a statement from the heart failure society of America Guidelines Committee. J Card Fail. 2015;21:519-34.

13. Crespo-Leiro MG, Metra M, Lund LH, Milicic D, Costanzo MR, Filippatos G, Gustafsson F, Tsui S, Barge-Caballero E, De Jonge N, Frigerio M, Hamdan R, Hasin T, Hulsmann M, Nalbantgil S, Potena L, Bauersachs J, Gkouziouta A, Ruhparwar A, Ristic AD, Straburzynska-Migaj E, McDonagh T, Seferovic P, Ruschitzka F. Advanced Heart failure: a position statement of the heart failure association of the European Society of Cardiology. Eur J Heart Fail. 2018;20:1505-35.

14. Stevenson LW, Pagani FD, Young JB, Jessup M, Miller L, Kormos RL, Naftel DC, Ulisney K, Desvigne-Nickens P, Kirklin JK. INTERMACS profiles of advanced heart failure: the current picture. J Heart Lung Transplant. 2009;28:535-41.

15. Metra M, Dinatolo E, Dasseni N. The new heart failure association definition of advanced heart failure. Card Fail Rev. 2019;5:5-8.

16. Yancy CW, Jessup M, Bozkurt B, Butler J, Casey DE Jr, Colvin MM, Drazner MH, Filippatos GS, Fonarow GC, Givertz MM, Hollenberg SM, Lindenfeld J, Masoudi FA, McBride PE, Peterson PN, Stevenson LW, Westlake C. 2017 ACC/AHA/HFSA Focused Update of the 2013 ACCF/AHA Guideline for the Management of Heart Failure: a report of the American College of cardiology/american heart association task force on cinical practice guidelines and the heart failure society of America. Circulation. 2017;136:e137-61.

17. Dunlay SM, Roger VL, Killian JM, Weston SA, Schulte PJ, Subramaniam $\mathrm{AV}$, Blecker $\mathrm{SB}$, Redfield $\mathrm{MM}$. Advanced heart failure epidemiology and outcomes: a population-based study. JACC Heart Fail. 2021;9:722-32.

18. Felker GM, Solomon SD, Claggett B, Diaz R, McMurray JJV, Metra M, Anand I, Crespo-Leiro MG, Dahlstrom U, Goncalvesova E, Howlett JG, MacDonald P, Parkhomenko A, Tomcsanyi J, Abbasi SA, Heitner SB, Hucko T, Kupfer S, Malik FI, Teerlink JR. Assessment of omecamtiv mecarbil for the treatment of patients with severe heart failure: a post hoc analysis of data from the GALACTIC-HF randomized clinical trial. JAMA Cardiol. 2021.

19. Bozkurt B, Coats AJS, Tsutsui H, Abdelhamid CM, Adamopoulos S, Albert N, Anker SD, Atherton J, Bohm M, Butler J, Drazner MH, Michael Felker G, Filippatos G, Fiuzat M, Fonarow GC, Gomez-Mesa JE, Heidenreich P, Imamura T, Jankowska EA, Januzzi J, Khazanie P, Kinugawa K, Lam CSP, Matsue Y, Metra M, Ohtani T, Francesco Piepoli M, Ponikowski P, Rosano GMC, Sakata Y, Seferovic P, Starling RC, Teerlink JR, Vardeny O, Yamamoto K, Yancy C, Zhang J, Zieroth S. Universal definition and classification of heart failure: a report of the heart failure society of America, heart failure association of the European society of cardiology, Japanese heart failure society and writing committee of the universal definition of heart failure: endorsed by the canadian heart failure society, heart failure association of india, cardiac society of australia and NEW Zealand, and Chinese heart failure association. Eur J Heart Fail. 2021;23:352-80.

20. Bjork JB, Alton KK, Georgiopoulou VV, Butler J, Kalogeropoulos AP. Defining advanced heart failure: a systematic review of criteria used in clinical trials. J Card Fail. 2016;22:569-77.

21. Gustafsson F. First Let's Try... will the success of new therapies paradoxically challenge outcomes in advanced heart failure? Circ Heart Fail. 2020;13:610.

22. Seferovic PM, Ponikowski P, Anker SD, Bauersachs J, Chioncel O, Cleland JGF, de Boer RA, Drexel H, Ben Gal T, Hill L, Jaarsma T, Jankowska EA, Anker MS, Lainscak M, Lewis BS, McDonagh T, Metra M, Milicic D, Mullens W, Piepoli MF,
Rosano G, Ruschitzka F, Volterrani M, Voors AA, Filippatos G, Coats AJS. Clinical Practice Update on Heart Failure 2019: pharmacotherapy, procedures, devices and patient management. An expert consensus meeting report of the heart failure association of the European society of cardiology. Eur J Heart Fail. 2019;21:1169-86.

23. McDonagh TA, Metra M, Adamo M, Gardner RS, Baumbach A, Bohm M, Burri H, Butler J, Celutkiene J, Chioncel O, Cleland JGF, Coats AJS, Crespo-Leiro MG, Farmakis D, Gilard M, Heymans S, Hoes AW, Jaarsma T, Jankowska EA, Lainscak M, Lam CSP, Lyon AR, McMurray JJV, Mebazaa A, Mindham R, Muneretto C, Francesco Piepoli M, Price S, Rosano GMC, Ruschitzka F, Kathrine Skibelund A and Group ESCSD. 2021 ESC guidelines for the diagnosis and treatment of acute and chronic heart failure. Eur Heart J. 2021;42:3599-3726.

24. Rosano GMC, Moura B, Metra M, Bohm M, Bauersachs J, Ben Gal T, Adamopoulos S, Abdelhamid M, Bistola V, Celutkiene J, Chioncel O, Farmakis D, Ferrari R, Filippatos G, Hill L, Jankowska EA, Jaarsma T, Jhund P, Lainscak M, Lopatin Y, Lund LH, Milicic D, Mullens W, Pinto F, Ponikowski P, Savarese G, Thum T, Volterrani M, Anker SD, Seferovic PM, Coats AJS. Patient profiling in heart failure for tailoring medical therapy. a consensus document of the heart failure association of the european society of cardiology. Eur J Heart Fail. 2021.

25. Ameri P, Bertero E, Maack C, Teerlink JR, Rosano G, Metra M. Medical treatment of heart failure with reduced ejection fraction: the dawn of a new era of personalized treatment? Eur Heart J Cardiovasc Pharmacother. 2021.

26. Komajda M. The euroheart failure survey programme—a survey on the quality of care among patients with heart failure in Europe part 2: treatment. Eur Heart J. 2003;24:464-74.

27. Komajda M, Lapuerta P, Hermans N, Gonzalez-Juanatey JR, van Veldhuisen DJ, Erdmann E, Tavazzi L, Poole-Wilson P, Le Pen C. Adherence to guidelines is a predictor of outcome in chronic heart failure: the MAHLER survey. Eur Heart J. 2005;26:1653-9.

28. Ouwerkerk W, Voors AA, Anker SD, Cleland JG, Dickstein K, Filippatos G, van der Harst P, Hillege HL, Lang CC, Ter Maaten JM, Ng LL, Ponikowski P, Samani NJ, van Veldhuisen DJ, Zannad F, Metra M, Zwinderman AH. Determinants and clinical outcome of uptitration of ace-inhibitors and beta-blockers in patients with heart failure: a prospective European study. Eur Heart J. 2017;38:1883-90.

29. Bistola V, Simitsis P, Parissis J, Ouwerkerk W, van Veldhuisen DJ, Cleland JG, Anker SD, Samani NJ, Metra M, Zannad F, Polyzogopoulou E, Keramida K, Farmakis D, Voors AA, Filippatos G. Association between up-titration of medical therapy and total hospitalizations and mortality in patients with recent worsening heart failure across the ejection fraction spectrum. Eur J Heart Fail. 2021.

30. Seferovic PM, Fragasso G, Petrie M, Mullens W, Ferrari R, Thum T, Bauersachs J, Anker SD, Ray R, Cavusoglu Y, Polovina M, Metra M, Ambrosio G, Prasad K, Seferovic J, Jhund PS, Dattilo G, Celutkiene J, Piepoli M, Moura B, Chioncel O, Ben Gal T, Heymans S, Jaarsma T, Hill L, Lopatin Y, Lyon AR, Ponikowski P, Lainscak M, Jankowska E, Mueller C, Cosentino F, Lund LH, Filippatos GS, Ruschitzka F, Coats AJS, Rosano GMC. Heart failure association of the european society of cardiology update on sodium-glucose co-transporter 2 inhibitors in heart failure. Eur J Heart Fail. 2020;22:1984-6.

31. Krum H. Role of renin in heart failure and therapeutic potential of direct renin inhibition. J Renin Angiotensin Aldosterone Syst. 2008;9:177-80.

32. Krum H, Maggioni A. Renin inhibitors in chronic heart failure: the aliskiren observation of heart failure treatment study in context. Clin Cardiol. 2010;33:536-41. 
33. King M, Kingery J, Casey B. Diagnosis and evaluation of heart failure. Am Family Phys. 2012;85:1161-68.

34. Packer M, Poole-Wilson P, Armstrong P, Cleland J, Horowitz J, Massie B, Ryde'n L, Thygesen K and Uretsky B. On behalf of the ATLAS Study Group. Comparative effects of low and high doses of the angiotensin-converting enzyme inhibitor, lisinopril, on morbidity and mortality in chronic heart failure. Circulation. 1999;100:2312-18.

35. Granger CB, McMurray JJV, Yusuf S, Held P, Michelson EL, Olofsson B, Östergren J, Pfeffer MA, Swedberg K. Effects of candesartan in patients with chronic heart failure and reduced left-ventricular systolic function intolerant to angiotensin-converting-enzyme inhibitors: the CHARM-alternative Trial. The Lancet. 2003;362:772-6.

36. Konstam MA, Neaton JD, Dickstein K, Drexler H, Komajda M, Martinez FA, Riegger GAJ, Malbecq W, Smith RD, Guptha $S$, Poole-Wilson PA. Effects of high-dose versus low-dose losartan on clinical outcomes in patients with heart failure (HEAAL study): a randomised double-blind trial. The Lancet. 2009;374:1840-8.

37. Pitt B, Segal R, Martinez F, Meurers G, Cowley A, Thomas I, Deedwania P, Ney D, Snavely D, Chang P. On behalf of ELITE Study Investigators. Randomised trial of losartan versus captopril in patients over 65 with heart failure (evaluation of losartan in the elderly study, ELITE). Lancet. 1997;349:747-752.

38. Pitt B, Poole-Wilson PA, Segal R, Martinez FA, Dickstein K, Camm AJ, Konstam MA, Riegger G, Klinger GH, Neaton J, Sharma D, Thiyagarajan B. Effect of Losartan compared with captopril on mortality in patients with symptomatic heart failure: randomised trial - the losartan heart failure survival study ELITE II. The Lancet. 2000;355:1582-7.

39. McMurray JJV, Östergren J, Swedberg K, Granger CB, Held P, Michelson EL, Olofsson B, Yusuf S, Pfeffer MA. Effects of candesartan in patients with chronic heart failure and reduced left-ventricular systolic function taking angiotensin-converting-enzyme inhibitors: the CHARM-added trial. The Lancet. 2003;362:767-71.

40. Effect of Metoprolol CR/XL in Chronic Heart Failure. Metoprolol CR/XL randomised intervention trial in-congestive heart Failure (MERIT-HF). The Lancet. 1999;353:2001-7.

41. Poole-Wilson PA, Swedberg K, Cleland JGF, Di Lenarda A, Hanrath P, Komajda M, Lubsen J, Lutiger B, Metra M, Remme WJ, Torp-Pedersen C, Scherhag A, Skene A. Comparison of carvedilol and metoprolol on clinical outcomes in patients with chronic heart failure in the carvedilol or metoprolol european trial (COMET): randomised controlled trial. The Lancet. 2003;362:7-13.

42. Packer M, Coats A, Fowler M, Katus H, Krum H, Mohacsi P, Rouleau J, Tendera M, Castaigne M, Roecker E, Schultz M, Demets D. For the Carvedilol prospective randomized cumulative survival study group. Effect of carvedilol on survival in severe chronic heart failure. NEJM. 2001;344:1651-58.

43. Flather MD, Shibata MC, Coats AJ, Van Veldhuisen DJ, Parkhomenko A, Borbola J, Cohen-Solal A, Dumitrascu D, Ferrari R, Lechat P, Soler-Soler J, Tavazzi L, Spinarova L, Toman J, Bohm M, Anker SD, Thompson SG, Poole-Wilson PA, Investigators S. Randomized trial to determine the effect of nebivolol on mortality and cardiovascular hospital admission in elderly patients with heart failure (SENIORS). Eur Heart J. 2005;26:215-25.

44. Juurlink D, Mamdani M, Lee D, Kopp A, Austin P, Laupacis A, Redelmeier D. Rates of hyperkalemia after publication of the randomized aldactone evaluation study. NEJM. 2004;351:543-51.

45. Svensson M, Gustafsson F, Galatius S, Hildebrandt P, Atar D. Hyperkalaemia and impaired renal function in patients taking spironolactone for congestive heart failure: retrospective study. BMJ. 2003;327:1141-2.
46. Liu LC, Schutte E, Gansevoort RT, van der Meer P, Voors AA. Finerenone: third-generation mineralocorticoid receptor antagonist for the treatment of heart failure and diabetic kidney disease. Expert Opin Investig Drugs. 2015;24:1123-35.

47. Bakris GL, Agarwal R, Anker SD, Pitt B, Ruilope LM, Rossing P, Kolkhof P, Nowack C, Schloemer P, Joseph A, Filippatos G, Investigators F-D. Effect of finerenone on chronic kidney disease outcomes in type 2 diabetes. N Engl J Med. 2020;383:2219-29.

48. Pitt B, Filippatos G, Agarwal R, Anker SD, Bakris GL, Rossing P, Joseph A, Kolkhof P, Nowack C, Schloemer P, Ruilope LM, Investigators F-D. Cardiovascular events with finerenone in kidney disease and type 2 diabetes. N Engl J Med. 2021; 2021:1.

49. O'Meara E, McDonald M, Chan M, Ducharme A, Ezekowitz JA, Giannetti N, Grzeslo A, Heckman GA, Howlett JG, Koshman SL, Lepage S, Mielniczuk LM, Moe GW, Swiggum E, Toma M, Virani SA, Zieroth S, De S, Matteau S, Parent MC, Asgar AW, Cohen G, Fine N, Davis M, Verma S, Cherney D, Abrams H, Al-Hesayen A, Cohen-Solal A, D'Astous M, Delgado DH, Desplantie O, Estrella-Holder E, Green L, Haddad H, Harkness K, Hernandez AF, Kouz S, LeBlanc MH, Lee D, Masoudi FA, McKelvie RS, Rajda M, Ross HJ, Sussex B. CCS/CHFS heart failure guidelines: clinical trial update on functional mitral regurgitation, SGLT2 Inhibitors, ARNI in HFpEF, and tafamidis in amyloidosis. Can J Cardiol. 2020;36:159-69.

50. Maddox TM, Januzzi JL, Allen LA, Breathett K, Butler J, Davis LL, Fonarow GC, Ibrahim NE, Lindenfeld J, Masoudi FA, Motiwala SR, Oliveros E, Patterson JH, Walsh MN, Wasserman A, Yancy CW, Youmans QR. 2021 update to the 2017 ACC expert consensus decision pathway for optimization of heart failure treatment: answers to 10 pivotal issues about heart failure with reduced ejection fraction. J Am Coll Cardiol. 2021;77:772-810.

51. McDonald M, Virani S, Chan M, Ducharme A, Ezekowitz JA, Giannetti N, Heckman GA, Howlett JG, Koshman SL, Lepage S, Mielniczuk L, Moe GW, O'Meara E, Swiggum E, Toma M, Zieroth S, Anderson K, Bray SA, Clarke B, Cohen-Solal A, D'Astous M, Davis M, De S, Grant ADM, Grzeslo A, Heshka J, Keen S, Kouz S, Lee D, Masoudi FA, McKelvie R, Parent MC, Poon S, Rajda M, Sharma A, Siatecki K, Storm K, Sussex B, Van Spall H, Yip AMC. CCS/CHFS heart failure guidelines update: defining a new pharmacologic standard of care for heart failure with reduced ejection fraction. Can J Cardiol. 2021;37:531-46.

52. Bhatt DL, Szarek M, Steg PG, Cannon CP, Leiter LA, McGuire DK, Lewis JB, Riddle MC, Voors AA, Metra M, Lund LH, Komajda M, Testani JM, Wilcox CS, Ponikowski P, Lopes RD, Verma S, Lapuerta P, Pitt B, Investigators S-WT. Sotagliflozin in patients with diabetes and recent worsening heart failure. $\mathrm{N}$ Engl J Med. 2021;384:117-128.

53. Damman K, Beusekamp JC, Boorsma EM, Swart HP, Smilde TDJ, Elvan A, van Eck JWM, Heerspink HJL, Voors AA. Randomized, double-blind, placebo-controlled, multicentre pilot study on the effects of empagliflozin on clinical outcomes in patients with acute decompensated heart failure (EMPA-RESPONSEAHF). Eur J Heart Fail. 2020;22:713-22.

54. Tromp J, Ponikowski P, Salsali A, Angermann CE, Biegus J, Blatchford J, Collins SP, Ferreira JP, Grauer C, Kosiborod M, Nassif ME, Psotka MA, Brueckmann M, Teerlink JR, Voors AA. Sodium-glucose co-transporter 2 inhibition in patients hospitalized for acute decompensated heart failure: rationale for and design of the EMPULSE trial. Eur J Heart Fail. 2021;23:826-34.

55. Griffin M, Rao VS, Ivey-Miranda J, Fleming J, Mahoney D, Maulion C, Suda N, Siwakoti K, Ahmad T, Jacoby D, Riello R, Bellumkonda L, Cox Z, Collins S, Jeon S, Turner JM, Wilson FP, Butler J, Inzucchi SE, Testani JM. Empagliflozin in heart failure: diuretic and cardiorenal effects. Circulation. 2020;142:1028-39.

56. Jensen J, Omar M, Kistorp C, Tuxen C, Gustafsson I, Køber L, Gustafsson F, Faber J, Malik ME, Fosbøl EL, Bruun NE, Forman 
JL, Jensen LT, Møller JE, Schou M. Effects of empagliflozin on estimated extracellular volume, estimated plasma volume, and measured glomerular filtration rate in patients with heart failure (empire HF renal): a prespecified substudy of a double-blind, randomised, placebo-controlled trial. Lancet Diabetes Endocrinol. 2021;9:106-16.

57. Jankowska EA, von Haehling S, Anker SD, Macdougall IC, Ponikowski P. Iron Deficiency and heart failure: diagnostic dilemmas and therapeutic perspectives. Eur Heart J. 2013;34:816-29.

58. Jankowska EA, Malyszko J, Ardehali H, Koc-Zorawska E, Banasiak W, von Haehling S, Macdougall IC, Weiss G, McMurray JJ, Anker SD, Gheorghiade M, Ponikowski P. Iron status in patients with chronic heart failure. Eur Heart J. 2013;34:827-34.

59. Anker S, Colet J, Filippatos G, Willenheimer R, Dickstein K, Drexler H, Lüscher T, Bart B, Banasiak W, Niegowska J, Kirwan B, Mori C, von Eisenhart Rothe B, Pocock S, Poole-Wilson P, Ponikowski P. For the FAIR-HF Trial Investigators. Ferric carboxymaltose in patients with heart failure and iron deficiency. NEJM. 2009;361:2436-48.

60. Ponikowski P, van Veldhuisen DJ, Comin-Colet J, Ertl G, Komajda M, Mareev V, McDonagh T, Parkhomenko A, Tavazzi L, Levesque V, Mori C, Roubert B, Filippatos G, Ruschitzka F, Anker SD, Investigators C-H. Beneficial effects of long-term intravenous iron therapy with ferric carboxymaltose in patients with symptomatic heart failure and iron deficiency dagger. Eur Heart J. 2015;36:657-68.

61. Ponikowski P, Kirwan B-A, Anker SD, McDonagh T, Dorobantu M, Drozdz J, Fabien V, Filippatos G, Göhring UM, Keren A, Khintibidze I, Kragten H, Martinez FA, Metra M, Milicic D, Nicolau JC, Ohlsson M, Parkhomenko A, Pascual-Figal DA, Ruschitzka F, Sim D, Skouri H, van der Meer P, Lewis BS, Comin-Colet J, von Haehling S, Cohen-Solal A, Danchin N, Doehner W, Dargie HJ, Motro M, Butler J, Friede T, Jensen KH, Pocock S, Jankowska EA, Azize G, Fernandez A, Zapata GO, Garcia Pacho P, Glenny A, Ferre Pacora F, Parody ML, Bono J, Beltrano C, Hershson A, Vita N, Luquez HA, Cestari HG, Fernandez H, Prado A, Berli M, García Durán R, Thierer J, Diez M, Lobo Marquez L, Borelli RR, Hominal M, Metra M, Ameri P, Agostoni P, Salvioni A, Fattore L, Gronda E, Ghio S, Turrini F, Uguccioni M, Di Biase M, Piepoli M, Savonitto S, Mortara A, Terrosu P, Fucili A, Boriani G, Midi P, Passamonti E, Cosmi F, van der Meer P, Van Bergen P, van de Wetering M, Al-Windy NYY, Tanis W, Meijs M, Groutars R, The HKS, Kietselaer B, van Kesteren HAM, Beelen DPW, Heymeriks J, Van de Wal R, Schaap J, Emans M, Westendorp P, Nierop PR, Nijmeijer R, Manintveld OC, Dorobantu M, Darabantiu DA, Zdrenghea D, Toader DM, Petrescu L, Militaru C, Crisu D, Tomescu MC, Stanciulescu G, Rodica Dan A, Iosipescu LC, Serban DL, Drozdz J, Szachniewicz J, Bronisz M, Tycińska A, Wozakowska-Kaplon B, Mirek-Bryniarska E, Gruchała M, Nessler J, StraburzyńskaMigaj E, Mizia-Stec K, Szelemej R, Gil R, Gąsior M, Gotsman I, Halabi M, Shochat M, Shechter M, Witzling V, Zukermann R, Arbel Y, Flugelman M, Ben-Gal T, Zvi V, Kinany W, Weinstein JM, Atar S, Goland S, Milicic D, Horvat D, Tušek S, Udovicic M, Šutalo K, Samodol A, Pesek K, Artuković M, Ružić A, Šikić J, McDonagh T, Trevelyan J, Wong YK, Gorog D, Ray R, Pettit S, Sharma S, Kabir A, Hamdan H, Tilling L, Baracioli L, Nigro Maia L, Dutra O, Reis G, Pimentel Filho P, Saraiva JF, Kormann A, dos Santos FR, Bodanese L, Almeida D, Precoma D, Rassi S, Costa F, Kabbani S, Abdelbaki K, Abdallah C, Arnaout MS, Azar R, Chaaban S, Raed O, Kiwan G, Hassouna B, Bardaji A, Zamorano J, del Prado S, Gonzalez Juanatey JR, Ga Bosa Ojeda FI, Gomez Bueno M, Molina BD, Pascual Figal DA, Sim D, Yeo TJ, Loh SY, Soon D, Ohlsson M, Smith JG, Gerward S, Khintibidze I, Lominadze Z, Chapidze G, Emukhvari N, Khabeishvili G, Chumburidze V, Paposhvili K, Shaburishvili T, Khabeishvili
G, Parhomenko O, Kraiz I, Koval O, Zolotaikina V, Malynovsky Y, Vakaliuk I, Rudenko L, Tseluyko V, Stanislavchuk M. Ferric carboxymaltose for iron deficiency at discharge after acute heart failure: a multicentre, double-blind, randomised, controlled trial. The Lancet. 2020;396:1895-1904.

62. van Veldhuisen DJ, de Graeff PA, Remme WJ, Lie KI. Value of digoxin in heart failure and sinus rhythm: new features of an old drug? J Am Coll Cardiol. 1996;28:813-9.

63. Packer M, Gheorghiade M, Young J, Costantini P, Adams K, Cody R, Smith L, Van Voorhees L, Gourley L, Jolly M. For the radiance study. Withdrawal of digoxin from patients with chronic heart failure treated with angiotensin-converting-enzyme inhibitors. NEJM. 1993;329:1-7.

64. The Digitalis Investigation Group. The effect of digoxin on mortality and morbidity in patients with heart failure. NEJM. 1997;336:525-33.

65. Bavendiek U, Berliner D, Davila LA, Schwab J, Maier L, Philipp SA, Rieth A, Westenfeld R, Piorkowski C, Weber K, Hanselmann A, Oldhafer M, Schallhorn S, von der Leyen H, Schroder C, Veltmann C, Stork S, Bohm M, Koch A, Bauersachs J, Investigators D-H and Committees. Rationale and design of the DIGIT-HF trial (DIGitoxin to improve outcomes in patients with advanced chronic heart failure): a randomized, double-blind, placebocontrolled study. Eur J Heart Fail. 2019;21:676-84.

66. Swedberg K, Komajda M, Böhm M, Borer JS, Ford I, DubostBrama A, Lerebours G, Tavazzi L. Ivabradine and outcomes in chronic heart failure (SHIFT): a randomised placebo-controlled study. The Lancet. 2010;376:875-85.

67. Kalmanovich E, Audurier Y, Akodad M, Mourad M, Battistella P, Agullo A, Gaudard P, Colson P, Rouviere P, Albat B, Ricci JE, Roubille F. Management of advanced heart failure: a review. Expert Rev Cardiovasc Ther. 2018;16:775-94.

68. Cohn J, Archibald D, Ziesche S, Franciosa J, Harston W, Tristani F, Dunkman W, Jacobs W, Francis G, Flohr K, Goldmand S, Cobb F, Shah P, Saunders R, Fletcher R, Loeb H, Hughes V, Baker B. Results of a veterans administration cooperative study. Effect of vasodilator therapy on mortality in chronic congestive heart failure. NEJM. 1986;314:1547-52.

69. Cohn J, Johnson G, Ziesche S, Cobb F, Francis G, Tristani F, Smith R, Dunkman W, Loeb H, Wong M, Bhat G, Goldman S, Fletcher R, Doherty J, Hughes V, Carson P, Cintron G, Shabetai $\mathrm{R}$, Haakenson C. A comparison of enalapril with hydralazineisosorbide dinitrate in the treatment of chronic congestive heart failure. NEJM. 1991;325:303-310.

70. Taylor A, Ziesche S, Yancy C, Carson P, D’Agostino Jr R, Ferdinand K, Taylor M, Adams K, Sabolinski M, Worcel M, Cohn J. For the African-American Heart Failure Trial Investigators. Combination of Isosorbide Dinitrate and Hydralazine in Blacks with Heart Failure. NEJM. 2004;351:2049-57.

71. Wiggers H, Kober L, Gislason G, Schou M, Poulsen MK, Vraa S, Nielsen OW, Bruun NE, Norrelund H, Hollingdal M, Barasa A, Bottcher M, Dodt K, Hansen VB, Nielsen G, Knudsen AS, Lomholdt J, Mikkelsen KV, Jonczy B, Bronnum-Schou J, Poenaru MP, Abdulla J, Raymond I, Mahboubi K, Sillesen K, Serup-Hansen K, Madsen JS, Kristensen SL, Larsen AH, Botker HE, Torp-Petersen C, Eiskjaer H, Moller J, Hassager C, Steffensen FH, Bibby BM, Refsgaard J, Hofsten DE, Mellemkjaer S, Gustafsson F. The DANish Randomized, Double-Blind, Placebo Controlled Trial in Patients With Chronic HEART Failure (DANHEART): a 2 × 2 factorial trial of hydralazine-isosorbide dinitrate in patients with chronic heart failure (H-HeFT) and metformin in patients with chronic heart failure and diabetes or prediabetes (Met-HeFT). Am Heart J. 2021;231:137-46.

72. Mullens W, Damman K, Harjola VP, Mebazaa A, Brunner-La Rocca HP, Martens P, Testani JM, Tang WHW, Orso F, Rossignol P, Metra M, Filippatos G, Seferovic PM, Ruschitzka F, 
Coats AJ. The use of diuretics in heart failure with congestion-a position statement from the heart failure association of the european society of cardiology. Eur J Heart Fail. 2019;21:137-55.

73. Chioncel O, Mebazaa A, Harjola V-P, Coats AJ, Piepoli MF, Crespo-Leiro MG, Laroche C, Seferovic PM, Anker SD, Ferrari R, Ruschitzka F, Lopez-Fernandez S, Miani D, Filippatos G, Maggioni AP. Clinical phenotypes and outcome of patients hospitalized for acute heart failure: the ESC Heart failure longterm registry. Eur J Heart Fail. 2017;19:1242-54.

74. Thom T, Haase N, Rosamond W, Howard VJ, Rumsfeld J, Manolio T, Zheng ZJ, Flegal K, O'Donnell C, Kittner S, Lloyd-Jones D, Goff DC, Jr., Hong Y, Adams R, Friday G, Furie K, Gorelick P, Kissela B, Marler J, Meigs J, Roger V, Sidney S, Sorlie P, Steinberger J, Wasserthiel-Smoller S, Wilson M, Wolf P, American Heart Association Statistics C and Stroke Statistics S. Heart Disease and Stroke Statistics-2006 Update: a report from the american heart association statistics committee and stroke statistics subcommittee. Circulation. 2006;113:e85-151.

75. Regolisti G, Antoniotti R, Pastorini G, Fani F, Fiaccadori E. Management of Congestion And Diuretic Resistance In Heart Failure. Nephrology. 2016;2016:2.

76. Brater D. Diuretic therapy. Drug Therapy. 1998;339:387-95.

77. McMurray JJ. Consensus to Emphasis: the overwhelming evidence which makes blockade of the renin-angiotensin-aldosterone system the cornerstone of therapy for systolic heart failure. Eur J Heart Fail. 2011;13:929-36.

78. Faris R, Flather M, Purcell H, Henein M, Poole-Wilson P, Coats A. Current evidence supporting the role of diuretics in heart failure: a meta analysis of randomised controlled trials. Int J Cardiol. 2002;82:149-58.

79. Lucas C, Johnson W, Hamilton MA, Fonarow GC, Woo MA, Flavell CM, Creaser JA, Stevenson LW. Freedom from congestion predicts good survival despite previous class IV symptoms of heart failure. Am Heart J. 2000;140:840-7.

80. Rubio-Gracia J, Demissei BG, Ter Maaten JM, Cleland JG, O'Connor CM, Metra M, Ponikowski P, Teerlink JR, Cotter G, Davison BA, Givertz MM, Bloomfield DM, Dittrich H, Damman K, Perez-Calvo JI, Voors AA. Prevalence, predictors and clinical outcome of residual congestion in acute decompensated heart failure. Int J Cardiol. 2018;258:185-91.

81. Rao VS, Planavsky N, Hanberg JS, Ahmad T, Brisco-Bacik MA, Wilson FP, Jacoby D, Chen M, Tang WHW, Cherney DZI, Ellison DH, Testani JM. Compensatory distal reabsorption drives diuretic resistance in human heart failure. J Am Soc Nephrol. 2017;28:3414-24.

82. Cook J, Smith D, Cornish L, Tankanow R, Nicklas J, Hyneck M. Kinetics, dynamics, and bioavailability of bumetanide in healthy subjects and patients with congestive heart failure. Clin Pharmacol Ther. 1988;44:487-500.

83. McCrindle J, Li Kamwa T, Barron W, Prescott L. Effect of food on the absorption of furosemide and bumetanide in man. $\mathrm{Br} \mathrm{J}$ Clin Pharmacol. 1996;42:743-6.

84. Aliti GB, Rabelo ER, Clausell N, Rohde LE, Biolo A, Beck-daSilva L. Aggressive fluid and sodium restriction in acute decompensated heart failure: a randomized clinical trial. JAMA Intern Med. 2013;173:1058-64.

85. Philipson H, Ekman I, Forslund HB, Swedberg K, Schaufelberger M. Salt and fluid restriction is effective in patients with chronic heart failure. Eur J Heart Fail. 2013;15:1304-10.

86. Kitsios GD, Mascari P, Ettunsi R, Gray AW. Co-administration of furosemide with albumin for overcoming diuretic resistance in patients with hypoalbuminemia: a meta-analysis. J Crit Care. 2014;29:253-9.

87. Felker G, Lee K, Bull D, Redfield M, Stevenson L, Goldsmith S, LeWinter M, Deswal A, Rouleau J, Ofili E, Anstrom K, Hernandez A, McNulty S, Velazquez E, Kfoury A, Chen H, Givertz
M, Semigran M, Bart B, Mascette A, Braunwald E, O’Connor C. For the NHLBI heart failure clinical research network. diuretic strategies in patients with acute decompensated heart failure. NEJM. 2011;364:797-805.

88. Metra M, Davison B, Bettari L, Sun H, Edwards C, Lazzarini V, Piovanelli B, Carubelli V, Bugatti S, Lombardi C, Cotter G, Dei $\mathrm{CL}$. Is Worsening renal function an ominous prognostic sign in patients with acute heart failure? The role of congestion and its interaction with renal function. Circ Heart Fail. 2012;5:54-62.

89. Testani JM, Chen J, McCauley BD, Kimmel SE, Shannon RP. Potential effects of aggressive decongestion during the treatment of decompensated heart failure on renal function and survival. Circulation. 2010;122:265-72.

90. Rosenberg J, Gustafsson F, Galatius S, Hildebrandt PR. Combination therapy with metolazone and loop diuretics in outpatients with refractory heart failure: an observational study and review of the literature. Cardiovasc Drugs Ther. 2005;19:301-6.

91. Channer K, McLean K, Lawson-Matthew P, Richardson M. Combination diuretic treatment in severe heart failure: a randomised controlled trial. Am Heart J. 1994;71:146-50.

92. Licata G, Di Pasquale P, Parrinello G, Cardinale A, Scandurra A, Follone G, Argano C, Tuttolomondo A, Paterna S. Effects of high-dose furosemide and small-volume hypertonic saline solution infusion in comparison with a high dose of furosemide as bolus in refractory congestive heart failure: long-term effects. Am Heart J. 2003;145:459-66.

93. Shulenberger CE, Jiang A, Devabhakthuni S, Ivaturi V, Liu $\mathrm{T}$, Reed BN. Efficacy and safety of intravenous chlorothiazide versus oral metolazone in patients with acute decompensated heart failure and loop diuretic resistance. Pharmacotherapy. 2016;36:852-60.

94. Ferreira JP, Eschalier R, Duarte K, Damman K, Gustafsson F, Schou M, Girerd N, Fay R, Tala S, Pitt B, Zannad F, Rossignol $P$. Reduced diuretic dose in patients treated with eplerenone: data from the EPHESUS trial. Circ Heart Fail. 2020;13:e006597.

95. Konstam M, Gheorghiade M, Burnett Jr J, Grinfeld L, Maggioni A, Swedberg K, Udelson J, Zannad F, Cook T, Ouyang J, Zimmer C, Cesare Orlandi O. For the efficacy of vasopressin antagonism in heart failure outcome study with tolvaptan (EVEREST) Investigators. Effects of oral tolvaptan in patients hospitalized for worsening heart failure. The EVEREST outcome trial. JAMA. 2007;297:1319-31.

96. Vishram-Nielsen JK, Gustafsson F. Vasopressin and vasopressin antagonists in heart failure. Handb Exp Pharmacol. 2017;243:307-28.

97. Balling L, Thomsen J, Wolsk E, Hassager C, Boesgaard S, Goldsmith S, Gustafsson F. Hemodynamic effects of short-term infusion of a vasopressin $\mathrm{V} 1 \mathrm{~A} / \mathrm{V} 2$ receptor antagonist conivaptan in patients with chronic heart failure during submaximal exercise. Am Heart J. 2018;203:101-4.

98. Goldsmith SR, Burkhoff D, Gustafsson F, Voors A, Zannad F, Kolkhof P, Staedtler G, Colorado P, Dinh W, Udelson JE. Dual vasopressin receptor antagonism to improve congestion in patients with acute heart failure: design of the AVANTI trial. J Card Fail. 2021;27:233-41.

99. Farmakis D, Agostoni P, Baholli L, Bautin A, Comin-Colet J, Crespo-Leiro MG, Fedele F, Garcia-Pinilla JM, Giannakoulas G, Grigioni F, Gruchala M, Gustafsson F, Harjola VP, Hasin T, Herpain A, Iliodromitis EK, Karason K, Kivikko M, Liaudet L, Ljubas-Macek J, Marini M, Masip J, Mebazaa A, Nikolaou M, Ostadal P, Poder P, Pollesello P, Polyzogopoulou E, Polzl G, Tschope C, Varpula M, von Lewinski D, Vrtovec B, Yilmaz MB, Zima E, Parissis J. A pragmatic approach to the use of inotropes for the management of acute and advanced heart failure: an expert panel consensus. Int J Cardiol. 2019;297:83-90. 
100. Hashim T, Sanam K, Revilla-Martinez M, Morgan CJ, Tallaj JA, Pamboukian SV, Loyaga-Rendon RY, George JF, Acharya D. Clinical characteristics and outcomes of intravenous inotropic therapy in advanced heart failure. Circ Heart Fail. 2015;8:880-6.

101. Cohn J, Goldstein S, Greenberg B, Lorell B, Bourge R, Jaski B, Gottlieb S, McGrew III F, DeMets D, White B, For the Vesnarinone Trial Investigators. A dose-dependent increase in mortality with vesnarinone among patients with severe heart failure. NEJM. 1998;339:1810-16.

102. Mebazaa A, Motiejunaite J, Gayat E, Crespo-Leiro MG, Lund LH, Maggioni AP, Chioncel O, Akiyama E, Harjola VP, Seferovic P, Laroche C, Julve MS, Roig E, Ruschitzka F, Filippatos G, Investigators ESCHFL-TR. Long-term safety of intravenous cardiovascular agents in acute heart failure: results from the European society of cardiology heart failure long-term registry. Eur J Heart Fail. 2018;20:332-41.

103. Nizamic T, Murad MH, Allen LA, McIlvennan CK, Wordingham SE, Matlock DD, Dunlay SM. Ambulatory inotrope infusions in advanced heart failure: a systematic review and meta-analysis. JACC Heart Fail. 2018;6:757-67.

104. Nanas JEPT, Kanakakis J, Nanas S, Terrovitis J, Moon T, Anastasiou-Nana M. Long-term intermittent dobutamine infusion, combined with oral amiodarone for end-stage heart failure. a randomized double-blind study. Eur J Heart Fail. 2004; 125:1198-204.

105. Thackray S, Easthaugh J, Freemantle N, Cleland J. The effectiveness and relative effectiveness of intravenous inotropic drugs acting through the adrenergic pathway in patients with heart failure-a meta-regression analysis. Eur J Heart Fail. 2002;4:515-29.

106. Tacon CL, McCaffrey J, Delaney A. Dobutamine for patients with severe heart failure: a systematic review and meta-analysis of randomised controlled trials. Intensive Care Med. 2012;38:359-67.

107. Martens P, Vercammen J, Ceyssens W, Jacobs L, Luwel E, Van Aerde H, Potargent P, Renaers M, Dupont M, Wilfried Mullens W. Effects of intravenous home dobutamine in palliative endstage heart failure on quality of life, heart failure hospitalization, and cost expenditure. ESC Heart Failure 2018;2018:5.

108. Chernomordik F, Freimark D, Arad M, Shechter M, Matetzky S, Savir Y, Shlomo N, Peled A, Goldenberg I, Peled Y. Quality of life and long-term mortality in patients with advanced chronic heart failure treated with intermittent low-dose intravenous inotropes in an outpatient setting. ESC Heart Fail. 2017;4:122-9.

109. Elkayam U, Ng TM, Hatamizadeh P, Janmohamed M, Mehra A. Renal vasodilatory action of dopamine in patients with heart failure: magnitude of effect and site of action. Circulation. 2008;117:200-5.

110. Giamouzis G, Butler J, Starling RC, Karayannis G, Nastas J, Parisis C, Rovithis D, Economou D, Savvatis K, Kirlidis T, Tsaknakis T, Skoularigis J, Westermann D, Tschope C, Triposkiadis F. Impact of dopamine infusion on renal function in hospitalized heart failure patients: results of the dopamine in acute decompensated heart failure (DAD-HF) trial. J Card Fail. 2010;16:922-30.

111. Chen HH, Anstrom KJ, Givertz MM, Stevenson LW, Semigran MJ, Goldsmith SR, Bart BA, Bull DA, Stehlik J, LeWinter MM, Konstam MA, Huggins GS, Rouleau JL, O'Meara E, Tang WH, Starling RC, Butler J, Deswal A, Felker GM, O'Connor CM, Bonita RE, Margulies KB, Cappola TP, Ofili EO, Mann DL, Davila-Roman VG, McNulty SE, Borlaug BA, Velazquez EJ, Lee KL, Shah MR, Hernandez AF, Braunwald E, Redfield MM, Network NHFCR. Low-dose dopamine or low-dose nesiritide in acute heart failure with renal dysfunction: the ROSE acute heart failure randomized trial. JAMA 2013;310:2533-43.
112. Shipley J, Tolman D, Hastillo A, Hess M. Milrinone: basic and clinical pharmacology and acute and chronic management. Review. 1996;311:286-91.

113. Packer M, Carver J, Rodeheffer R, Ivanhoe R, DiBianco R, Zeldis S, Hendrix G, Bommer W, Elkayam U, Kukin M, Mallis G, Sollano J, Shannon J, Tandon P, DeMets D. For the PROMISE study research group. effect of oral milrinone on mortality in severe chronic heart failure. NEJM. 1991;325:1468-75.

114. Cuffe M, Califf R, Adams Jr K, Benza R, Bourge R, Colucci W, Massie B, O'Connor C, Pina I, Quigg R, Silver M, Gheorghiade M. For the outcomes of a prospective trial of intravenous milrinone for exacerbations of chronic heart failure (OPTIME-CHF) Investigators. Short-term intravenous milrinone for acute exacerbation of chronic heart failure. A randomized controlled trial. JAMA. 2002;287:1541-47.

115. Felker GM, Benza RL, Chandler AB, Leimberger JD, Cuffe MS, Califf RM, Gheorghiade M, O'Connor CM. Heart failure etiology and response tomilrinone in decompensated heart failure. $\mathrm{J}$ Am Coll Cardiol. 2003;41:997-1003.

116. Nanayakkara S, Mak V, Crannitch K, Byrne M, Kaye DM. Extended release oral milrinone, CRD-102, for advanced heart failure. Am J Cardiol. 2018;122:1017-20.

117. Blondheim D, Jacobs L, Kotler M, Costacurta G, Parry W. Clinical pharmacology of intravenous enoximone: pharmacodynamics and pharmacokinetics in patients with heart failure. Am Heart J. 1991;122:755-63.

118. Metra M, Eichhorn E, Abraham WT, Linseman J, Bohm M, Corbalan R, DeMets D, De Marco T, Elkayam U, Gerber M, Komajda M, Liu P, Mareev V, Perrone SV, Poole-Wilson P, Roecker E, Stewart J, Swedberg K, Tendera M, Wiens B, Bristow MR, Investigators E. Effects of low-dose oral enoximone administration on mortality, morbidity, and exercise capacity in patients with advanced heart failure: the randomized, double-blind, placebo-controlled, parallel group ESSENTIAL trials. Eur Heart J. 2009;30:3015-26.

119. Follath F, Cleland J, Just H, Papp J, Scholz H, Peuhkurinen K, Harjola V, Mitrovic V, Abdalla M, Sandell E, Lehtonen L. For the Steering Committee and Investigators of the Levosimendan Infusion versus Dobutamine (LIDO) Study. Efficacy and safety of intravenous levosimendan compared with dobutamine in severe low-output heart failure (the LIDO study): a randomised doubleblind trial. Eur Heart J 2002;360:196-202.

120. Pollesello P, Parissis J, Kivikko M, Harjola VP. Levosimendan meta-analyses: is there a pattern in the effect on mortality? Int $\mathrm{J}$ Cardiol. 2016;209:77-83.

121. Mebazaa A, Nieminen M, Packer M, Cohen-Solal A, Kleber F, Pocock S, Thakkar R, Padley R, Po ${ }^{\sim}$ der P and Kivikko M. Levosimendan vs dobutamine for patients with acute decompensated heart failure. The SURVIVE randomized trial. JAMA. 2007;297:1883-91.

122. Packer M, Colucci W, Fisher L, Massie BM, Teerlink JR, Young J, Padley RJ, Thakkar R, Delgado-Herrera L, Salon J, Garratt C, Huang B, Sarapohja T, Group RHFS. Effect of levosimendan on the short-term clinical course of patients with acutely decompensated heart failure. JACC Heart Fail. 2013;1:103-11.

123. Moiseyev VS, Poder P, Andrejevs N, Ruda MY, Golikov AP, Lazebnik LB, Kobalava ZD, Lehtonen LA, Laine T, Nieminen MS, Lie KI, Investigators RS. Safety and efficacy of a novel calcium sensitizer, levosimendan, in patients with left ventricular failure due to an acute myocardial infarction. A randomized, placebo-controlled, double-blind study (RUSSLAN). Eur Heart J. 2002;23:1422-32.

124. Nieminen MS, Cleland JG, Eha J, Belenkov Y, Kivikko M, Poder P, Sarapohja T. Oral Levosimendan in patients with severe chronic heart failure-the PERSIST study. Eur J Heart Fail. 2008;10:1246-54. 
125. Altenberger J, Parissis JT, Costard-Jaeckle A, Winter A, Ebner C, Karavidas A, Sihorsch K, Avgeropoulou E, Weber T, Dimopoulos L, Ulmer H, Poelzl G. Efficacy and safety of the pulsed infusions of levosimendan in outpatients with advanced heart failure (LevoRep) study: a multicentre randomized trial. Eur J Heart Fail. 2014;16:898-906.

126. Comin-Colet J, Manito N, Segovia-Cubero J, Delgado J, Garcia Pinilla JM, Almenar L, Crespo-Leiro MG, Sionis A, Blasco T, Pascual-Figal D, Gonzalez-Vilchez F, Lambert-Rodriguez JL, Grau M, Bruguera J and Investigators L-HS. Efficacy and safety of intermittent intravenous outpatient administration of levosimendan in patients with advanced heart failure: the LION-HEART multicentre randomised trial. Eur J Heart Fail. 2018;20:1128-36.

127. Garcia-Gonzalez MJ, de Mora-Martin M, Lopez-Fernandez S, Lopez-Diaz J, Martinez-Selles M, Romero-Garcia J, Cordero M, Lara-Padron A, Marrero-Rodriguez F, del Mar Garcia-Saiz M, Aldea-Perona A and investigators Ls. Rationale and Design of a randomized, double-blind, placebo controlled multicenter trial to study efficacy, security, and long term effects of intermittent repeated levosimendan administration in patients with advanced heart failure: LAICA Study. Cardiovasc Drugs Ther. 2013;27:573-9.

128. Oliva F, Comin-Colet J, Fedele F, Fruhwald F, Gustafsson F, Kivikko M, Borbely A, Polzl G, Tschope C. Repetitive Levosimendan Treatment In The Management Of Advanced Heart Failure. Eur Heart J Suppl. 2018;20:I11-20.

129. Silvetti S, Nieminen MS. Repeated or intermittent levosimendan treatment in advanced heart failure: an updated meta-analysis. Int J Cardiol. 2016;202:138-43.

130. Silvetti S, Belletti A, Fontana A, Pollesello P. Rehospitalization after intermittent levosimendan treatment in advanced heart failure patients: a meta-analysis of randomized trials. ESC Heart Fail. 2017;4:595-604.

131. Polzl G, Altenberger J, Baholli L, Beltran P, Borbely A, Comin-Colet J, Delgado JF, Fedele F, Fontana A, Fruhwald F, Giamouzis G, Giannakoulas G, Garcia-Gonzalez MJ, Gustafsson F, Kaikkonen K, Kivikko M, Kubica J, von Lewinski D, Lofman I, Malfatto G, Manito N, Martinez-Selles M, Masip J, Merkely B, Morandi F, Molgaard H, Oliva F, Pantev E, Papp Z, Perna GP, Pfister R, Piazza V, Bover R, Rangel-Sousa D, Recio-Mayoral A, Reinecke A, Rieth A, Sarapohja T, Schmidt G, Seidel M, Stork S, Vrtovec B, Wikstrom G, Yerly P, Pollesello P. Repetitive use of levosimendan in advanced heart failure: need for stronger evidence in a field in dire need of a useful therapy. Int J Cardiol. 2017;243:389-95.

132. Pölzl G, Allipour Birgani S, Comín-Colet J, Delgado JF, Fedele F, García-Gonzáles MJ, Gustafsson F, Masip J, Papp Z, Störk S, Ulmer H, Vrtovec B, Wikström G, Altenberger J. Repetitive levosimendan infusions for patients with advanced chronic heart failure in the vulnerable post-discharge period. ESC Heart Fail. 2019;6:174-81.

133. Teerlink J, Felker G, McMurray J, Solomon S, Adams Jr K, Cleland J, Ezekowitz J, Goudev A, Macdonald P, Metra M, Mitrovic V, Ponikowski P, Serpytis P, Spinar J, Tomcsányi J, Vandekerckhove H, Voors A, Monsalvo M, Johnston J, Malik F, Honarpour N, For the COSMIC-HF Investigators. Chronic oral study of myosin activation to increase contractility in heart failure (COSMIC-HF): a phase 2, pharmacokinetic, randomised, placebo-controlled trial. Lancet. 2016;388:2895-2903.

134. Felker GM, Solomon SD, McMurray JJV, Cleland JGF, Abbasi SA, Malik FI, Zhang H, Globe G, Teerlink JR, Investigators C-H. Effects of omecamtiv mecarbil on symptoms and health-related quality of life in patients with chronic heart failure: results from the COSMIC-HF study. Circ Heart Fail. 2020;13:814.
135. Teerlink JR, Diaz R, Felker GM, McMurray JJV, Metra M, Solomon SD, Adams KF, Anand I, Arias-Mendoza A, BieringSorensen T, Bohm M, Bonderman D, Cleland JGF, Corbalan R, Crespo-Leiro MG, Dahlstrom U, Echeverria LE, Fang JC, Filippatos G, Fonseca C, Goncalvesova E, Goudev AR, Howlett JG, Lanfear DE, Li J, Lund M, Macdonald P, Mareev V, Momomura SI, O'Meara E, Parkhomenko A, Ponikowski P, Ramires FJA, Serpytis P, Sliwa K, Spinar J, Suter TM, Tomcsanyi J, Vandekerckhove H, Vinereanu D, Voors AA, Yilmaz MB, Zannad F, Sharpsten L, Legg JC, Varin C, Honarpour N, Abbasi SA, Malik FI, Kurtz CE, Investigators G-H. Cardiac myosin activation with omecamtiv mecarbil in systolic heart failure. N Engl J Med. 2021;384:105-16.

136. Teerlink JR, Diaz R, Felker GM, McMurray JJV, Metra M, Solomon SD, Biering-Sorensen T, Bohm M, Bonderman D, Fang JC, Lanfear DE, Lund M, Momomura SI, O'Meara E, Ponikowski P, Spinar J, Flores-Arredondo JH, Claggett BL, Heitner SB, Kupfer S, Abbasi SA, Malik FI, Investigators G-H. Effect of ejection fraction on clinical outcomes in patients treated with omecamtiv mecarbil in GALACTIC-HF. J Am Coll Cardiol. 2021;78:97-108.

137. Armstrong PW, Pieske B, Anstrom KJ, Ezekowitz J, Hernandez AF, Butler J, Lam CSP, Ponikowski P, Voors AA, Jia G, McNulty SE, Patel MJ, Roessig L, Koglin J, O’Connor CM, Group VS. Vericiguat in patients with heart failure and reduced ejection fraction. N Engl J Med. 2020;382:1883-93.

138. Ezekowitz JA, O'Connor CM, Troughton RW, Alemayehu WG, Westerhout CM, Voors AA, Butler J, Lam CSP, Ponikowski P, Emdin M, Patel MJ, Pieske B, Roessig L, Hernandez AF, Armstrong PW. N-Terminal Pro-B-type natriuretic peptide and clinical outcomes: vericiguat heart failure with reduced ejection fraction study. JACC Heart Fail. 2020;8:931-9.

139. Alba AC, Delgado DH. The future is here: ventricular assist devices for the failing heart. Expert Rev Cardiovasc Ther. 2009;7:1067-77.

140. Kirklin JK, Naftel DC, Pagani FD, Kormos RL, Stevenson LW, Blume ED, Myers SL, Miller MA, Baldwin JT, Young JB. Seventh INTERMACS annual report: 15000 patients and counting. J Heart Lung Transplant. 2015;34:1495-504.

141. Zimpfer D, Gustafsson F, Potapov E, Pya Y, Schmitto J, Berchtold-Herz M, Morshuis M, Shaw SM, Saeed D, Lavee J, Heatley G, Gazzola C, Garbade J. Two-year outcome after implantation of a full magnetically levitated left ventricular assist device: results from the ELEVATE registry. Eur Heart J. 2020;41:3801-9.

142. Potapov EV, Antonides C, Crespo-Leiro MG, Combes A, Farber G, Hannan MM, Kukucka M, de Jonge N, Loforte A, Lund LH, Mohacsi P, Morshuis M, Netuka I, Ozbaran M, Pappalardo F, Scandroglio AM, Schweiger M, Tsui S, Zimpfer D, Gustafsson F. 2019 EACTS expert consensus on long-term mechanical circulatory support. Eur J Cardiothorac Surg. 2019;56:230-70.

143. Nassif ME, Tibrewala A, Raymer DS, Andruska A, Novak E, Vader JM, Itoh A, Silvestry SC, Ewald GA, LaRue SJ. Systolic blood pressure on discharge after left ventricular assist device insertion is associated with subsequent stroke. J Heart Lung Transplant. 2015;34:503-8.

144. Slaughter M, Rogers J, Milano C, Russell S, Conte J, Feldman D, Sun B, Tatooles A, Delgado R III, Long J, Wozniak T, Ghumman W, Farrar D, Frazier O. For the HeartMate II Investigators. Advanced Heart failure treated with continuous-flow left ventricular assist device. NEJM. 2009;361:2241-51.

145. Kirklin JK, Pagani FD, Kormos RL, Stevenson LW, Blume ED, Myers SL, Miller MA, Baldwin JT, Young JB, Naftel DC. Eighth annual INTERMACS report: special focus on framing the impact of adverse events. J Heart Lung Transplant. 2017;36:1080-6. 
146. Patil NP, Mohite PN, Sabashnikov A, Dhar D, Weymann A, Zeriouh M, Koch A, Garcia-Saez D, Zych B, Hards R, Hedger M, De Robertis F, Moza A, Bahrami T, Amrani M, Rahman-Haley S, Popov AF, Banner N, Simon AR. Does postoperative blood pressure influence development of aortic regurgitation following continuous-flow left ventricular assist device implantation? Dagger. Eur J Cardiothorac Surg. 2016;49:788-94.

147. Milano CA, Rogers JG, Tatooles AJ, Bhat G, Slaughter MS, Birks EJ, Mokadam NA, Mahr C, Miller JS, Markham DW, Jeevanandam V, Uriel N, Aaronson KD, Vassiliades TA, Pagani FD, Investigators E. HVAD: the ENDURANCE supplemental trial. JACC Heart Fail. 2018;6:792-802.

148. Kirklin JK, Naftel DC, Pagani FD, Kormos RL, Stevenson LW, Blume ED, Miller MA, Baldwin JT, Young JB. Sixth INTERMACS annual report: a 10,000-patient database. J Heart Lung Transplant. 2014;33:555-64.

149. Mehra MR, Cleveland JC, Jr., Uriel N, Cowger JA, Hall S, Horstmanshof D, Naka Y, Salerno CT, Chuang J, Williams C, Goldstein DJ and on behalf of the MI. Primary results of longterm outcomes in the MOMENTUM 3 pivotal trial and continued access protocol study phase: a study of 2200 HeartMate 3 Left Ventricular Assist Device Implants. Eur J Heart Fail. 2021;23:1392-400.

150. Lanier GM, Orlanes K, Hayashi Y, Murphy J, Flannery M, Te-Frey R, Uriel N, Yuzefpolskaya M, Mancini DM, Naka Y, Takayama H, Jorde UP, Demmer RT, Colombo PC. Validity and reliability of a novel slow cuff-deflation system for noninvasive blood pressure monitoring in patients with continuous-flow left ventricular assist device. Circ Heart Fail. 2013;6:1005-12.

151. Dobarro D, Diez-Lopez C, Couto-Mallon D, Castrodeza J, Gomez-Bueno M, Tobar J, McKenzie S, Goncalves A, MelendoViu M, Ortiz C, Gonzalez-Costello J. Use of sacubitril-valsartan in blood pressure control with left ventricular assist devices. JHLT. 2020;39:1499-501.

152. Goldberg R, Freed K, Klemans N, Fioretti R, Choi C, Kilic A, Adamo L, Florido R, Sharma K, Gilotra N, Hsu S. Angiotensin receptor-neprilysin inhibition improves blood pressure and heart failure control in left ventricular assist device patients. ASAIO. 2021. https://doi.org/10.1097/MAT.0000000000001435.

153. Randhawa V, West L, Luthman J, Estep J, Soltesz E, Starling R. Sacubitril/valsartan in patients post-left ventricular assist device implant: a single-centre case series. Eur J Heart Fail. 2020;22:1490-2.

154. Lampert BC, Eckert C, Weaver S, Scanlon A, Lockard K, Allen C, Kunz N, Bermudez C, Bhama JK, Shullo MA, Kormos RL, Dew MA, Teuteberg JJ. Blood pressure control in continuous flow left ventricular assist devices: efficacy and impact on adverse events. Ann Thorac Surg. 2014;97:139-46.

155. Feldman D, Pamboukian SV, Teuteberg JJ, Birks E, Lietz K, Moore SA, Morgan JA, Arabia F, Bauman ME, Buchholz HW, Deng M, Dickstein ML, El-Banayosy A, Elliot T, Goldstein DJ, Grady KL, Jones K, Hryniewicz K, John R, Kaan A, Kusne S, Loebe M, Massicotte MP, Moazami N, Mohacsi P, Mooney M, Nelson T, Pagani F, Perry W, Potapov EV, Eduardo Rame J, Russell SD, Sorensen EN, Sun B, Strueber M, Mangi AA, Petty MG, Rogers J, International Society for $\mathrm{H}$ and Lung T. The 2013 international society for heart and lung transplantation guidelines for mechanical circulatory support: executive summary. J Heart Lung Transplant. 2013;32:157-87.

156. Takeda K, Takayama H, Colombo PC, Yuzefpolskaya M, Fukuhara S, Han J, Kurlansky P, Mancini DM, Naka Y. Incidence and clinical significance of late right heart failure during continuousflow left ventricular assist device support. J Heart Lung Transplant. 2015;34:1024-32.
157. Takeda K, Takayama H, Colombo PC, Jorde UP, Yuzefpolskaya M, Fukuhara S, Mancini DM, Naka Y. Late right heart failure during support with continuous-flow left ventricular assist devices adversely affects post-transplant outcome. J Heart Lung Transplant. 2015;34:667-74.

158. Kormos RL, Teuteberg JJ, Pagani FD, Russell SD, John R, Miller LW, Massey T, Milano CA, Moazami N, Sundareswaran KS, Farrar DJ, HeartMate IICI. Right ventricular failure in patients with the heartmate II continuous-flow left ventricular assist device: incidence, risk factors, and effect on outcomes. J Thorac Cardiovasc Surg. 2010;139:1316-24.

159. Frankfurter C, Molinero M, Vishram-Nielsen JKK, Foroutan F, Mak S, Rao V, Billia F, Orchanian-Cheff A, Alba AC. Predicting the risk of right ventricular failure in patients undergoing left ventricular assist device implantation: a systematic review. Circ Heart Fail. 2020;13:e06994.

160. Uriel N, Burkhoff D, Kim G, Silverstein T, Juricek C, Kaye DM, Sayer G. Oral milrinone for the treatment of chronic severe right ventricular failure in left ventricular assist device patients. Circ Heart Fail. 2021;14:e007286.

161. Smith LA, Yarboro LT, Kennedy JL. Left ventricular assist device implantation strategies and outcomes. J Thorac Dis. 2015;7:2088-96.

162. Topkara VK, Garan AR, Fine B, Godier-Furnemont AF, Breskin A, Cagliostro B, Yuzefpolskaya M, Takeda K, Takayama H, Mancini DM, Naka Y, Colombo PC. Myocardial recovery in patients receiving contemporary left ventricular assist devices: results from the interagency registry for mechanically assisted circulatory support (INTERMACS). Circ Heart Fail. 2016;2016:9.

163. Mancini D, Beniaminovitz A, Levin H, Catanese K, Flannery M, DiTullio M, Savin S, Cordisco M, Rose E, Oz M. Low incidence of myocardial recovery after left ventricular assist device implantation in patients with chronic heart failure. Circulation. 1998;98:2383-9.

164. Dandel M, Weng Y, Siniawski H, Stepanenko A, Krabatsch T, Potapov E, Lehmkuhl HB, Knosalla C, Hetzer R. Heart failure reversal by ventricular unloading in patients with chronic cardiomyopathy: criteria for weaning from ventricular assist devices. Eur Heart J. 2011;32:1148-60.

165. Birks EJ, Drakos SG, Patel SR, Lowes BD, Selzman CH, Starling RC, Trivedi J, Slaughter MS, Alturi P, Goldstein D, Maybaum S, Um JY, Margulies KB, Stehlik J, Cunningham C, Farrar DJ, Rame JE. Prospective multicenter study of myocardial recovery using left ventricular assist devices (RESTAGE-HF [Remission from Stage D Heart Failure]): medium-term and primary end point results. Circulation. 2020;142:2016-28.

166. Birks EJ, George RS, Hedger M, Bahrami T, Wilton P, Bowles CT, Webb C, Bougard R, Amrani M, Yacoub MH, Dreyfus G, Khaghani A. Reversal of severe heart failure with a continuousflow left ventricular assist device and pharmacological therapy: a prospective study. Circulation. 2011;123:381-90.

167. Patel SR, Saeed O, Murthy S, Bhatia V, Shin JJ, Wang D, Negassa A, Pullman J, Goldstein DJ, Maybaum S. Combining neurohormonal blockade with continuous-flow left ventricular assist device support for myocardial recovery: a single-arm prospective study. J Heart Lung Transplant. 2013;32:305-12.

168. Dridi NP, Vishram-Nielsen JKK, Gustafsson F. Exercise tolerance in patients treated with a durable left ventricular assist device: importance of myocardial recovery. J Card Fail. 2021;27:486-93. 